\title{
SELECTION ON FLORAL MORPHOLOGY AND ENVIRONMENTAL DETERMINANTS OF FECUNDITY IN A HAWK MOTH-POLLINATED VIOLET ${ }^{1}$
}

\author{
CARlos M. Herrera \\ Estación Biológica de Doñana, Apartado 1056, E-41080 Sevilla, Spain
}

Abstract. This paper presents the results of a 5-yr field study on the determinants of individual variation in maternal fecundity (seed production) in the narrowly endemic violet Viola cazorlensis (Violaceae), at a southeastern Spanish locality. Flowers of this species are characterized by a very long, thin spur and broad morphological variability, and are pollinated by a single species of day-flying hawk moth (Macroglossum stellatarum; Lepidoptera, Sphingidae). The primary aim of this investigation was to answer the question, What are the relative importances, as explanations of individual differences in fecundity, of variability in floral traits and of other fecundity determinants that are of an extrinsic nature, such as microhabitat type and interactions with herbivores? The floral morphology of individual $V$. cazorlensis plants was characterized by means of both "conventional," linear measurements of the size of flower parts (petals, spur, peduncle), and shape analysis of corolla outline (using thin-plate splines relative warps analysis). Spatial (among substrate types) and temporal (among years) patterns of variation in flower, fruit, and seed production by $V$. cazorlensis plants are described, with particular emphasis on the comparative effects of floral morphology, herbivory (by mammalian ungulates and two species of lepidopteran larvae), and substrate type (rock cliffs, bare rocks at ground level, and sandy soils), on cumulative seed production at the individual plant level.

Cumulative seed production of individual $V$. cazorlensis plants depended significantly on average floral morphology (both size and shape components), thus revealing the existence of phenotypic selection on the floral morphology of this species at the study population. Among all the floral traits examined, spur length was the only one for which no significant relationship with fecundity was found. Type of substrate largely determined differences between $V$. cazorlensis plants in the impact of herbivory (plants growing on the soil exhibited the greatest reproductive losses to herbivores), and it also influenced plant size and flower production per reproductive episode. Plant size, in turn, influenced the supra-annual frequency of flowering and the number of flowers produced in each reproductive event. Flower production and herbivory levels significantly influenced (positively and negatively, respectively) fruit number, which was the major direct determinant of seed production. Path analysis revealed that the main determinants of individual variation in cumulative seed production over the study period were, in decreasing order of importance (absolute value of "effect coefficient" in parentheses), cumulative fruit production (0.946), mean flower production per reproductive event $(0.868)$, plant size $(0.441)$, herbivory by ungulates $(-0.221)$, and average score on the first relative warp (0.107), a descriptor of flower shape. After accounting for the effects of substrate type, herbivory, plant size, and flower and fruit production, individual variation in floral morphology (aspects of size and shape) explained a negligible proportion (2.1\%) of total individual variation in cumulative fruit production. Phenotypic selection on the floral morphology of $V$. cazorlensis at the study population, although statistically significant, was therefore almost inconsequential as a source of individual variation in maternal fitness, its effects being heavily "diluted" by the overwhelming influence of other factors. As exemplified by this study, selection on the floral phenotype may often become largely irrelevant in evolutionary terms because other ecological factors are far more important determinants of fitness differences among plants. A realistic assessment of the potential relevance of selection on plant reproductive traits thus requires a quantitative evaluation, in its natural scenario, of the predictable consequences of such selection.

Key words: endemic plants; fecundity determinants; floral morphology; flower shape; herbivory; monophily; path analysis; phenotypic selection; pollination; relative warp analysis; seed production; shape analysis; Sphingidae; Violaceae. 


\section{INTRODUCTION}

Assessing the adaptive significance of reproductive traits has figured prominently among the objectives of studies on plant ecology in the last few decades (for reviews see, e.g., Howe and Smallwood 1982, Real 1983, Rathcke and Lacey 1985, Lovett Doust and Lovett Doust 1988). Rigorous tests of adaptive interpretations of plant reproductive traits require, at least, (1) the existence of some variation in the trait under consideration, either occurring naturally or induced by experimental manipulation; and (2) demonstration that such variation influences plant fitness, generally measured in terms of differential reproductive success. When trait variation occurs naturally and the units under comparison are individual genotypes (i.e., reproductive success is measured on a per plant basis), studies satisfying conditions 1 and 2 above are apt to detect selection in natural plant populations (Lande and Arnold 1983, Arnold and Wade 1984a, $b$, Crespi and Bookstein 1989, Crespi 1990). This "phenotypic selection" approach has its foundation on the conceptual distinction between selection and evolutionary response to selection, the former being described in purely phenotypic terms (variability among phenotypes in fitness), without recourse to the inheritance of characters (Lande and Arnold 1983, Arnold and Wade $1984 a$ ). Despite some disagreements on aspects of method and interpretation (Mitchell-Olds and Shaw 1987, 1990, Schluter 1988, Crespi and Bookstein 1989, Crespi 1990, Wade and Kalisz 1990), the phenotypic selection approach has been widely adopted by investigators inquiring into the evolutionary significance of phenotypic traits. Recent studies following this approach have been most successful in documenting the evolutionary significance of within-population variation in plant reproductive traits like, for instance, phenology (Kalisz 1986, Biere 1991, Dieringer 1991, Galen and Stanton 1991, Widén 1991, Herrera 1992a) and floral morphology (Galen et al. 1987, Galen and Newport 1987, Nilsson 1988, Galen 1989, Herrera $1990 a$, Robertson and Wyatt 1990, Campbell et al. 1991, Johnston 1991, Stanton et al. 1991).

These and other investigations have illustrated relationships between reproductive success (as an estimate of fitness) and reproductive traits. Most often, however, they have not evaluated the proportional importance of variation in reproductive traits in relation to other concurrent factors that may also influence reproductive success in natural populations. Even if variation in a given reproductive trait is significantly correlated with differential reproductive success, the proportion of within-population variance in reproductive success explained by that attribute may vary widely, depending on the relative importance of other factors (Thompson 1983, Herrera 1988a, Schemske and Horvitz 1988, Thompson and Pellmyr 1989). In Arnold and Wade's (1984a) terminology, studies of selection on plant reproductive attributes have often shown that a statistically significant proportion of the "opportunity for selection" (the variance in fitness) depends on the existence of individual variation in reproductive attributes, but the magnitude of this proportion has rarely been evaluated. This fact has both methodological and conceptual implications. First, ignoring extrinsic factors that affect fitness may complicate, or even invalidate, inferences regarding selection. As stated by Mitchell-Olds and Shaw (1987:1154), “in the same way that unmeasured phenotypic characters may bias selection estimates, failure to consider environmental factors that simultaneously affect characters and individual fitness will also bias estimates of selection gradients." And second, the inclusion in selection analyses, in addition to reproductive traits, of as many ecological factors as possible that affect fitness, will provide more realistic estimates of the proportion of the opportunity for selection that is uniquely due to phenotypic variability in reproductive traits (MitchellOlds and Shaw 1987, Crespi 1990).

Inquiries into the adaptive value of plant reproductive traits should thus attempt to answer not only the question, Is there a significant relationship between individual variation in reproductive success and the reproductive trait of interest?, but also, What is the relative importance of variation in reproductive traits in explaining differential reproductive success under natural conditions? This would require the following additional steps: (3) identifying as many factors as possible that influence significantly individual variation in reproductive success under natural conditions; (4) elucidating their mutual relationships, and quantifying their combined influence on within-population variance in reproductive success; and (5) determining the relative importance of variation in reproductive traits in explaining differences in reproductive success. While the identification of relationships between reproductive traits and reproductive success (steps 1-2) can be, and often is, conducted on experimental plant populations, the assessment of the relative importance of variation in reproductive traits with respect to other ecological factors (steps 3-5) requires the study of natural populations.

\section{Objectives of the study}

This paper presents the results of a 5-yr field study on the determinants of individual variation in maternal fecundity in Viola cazorlensis (Violaceae) at a southeastern Spanish locality (throughout this paper, "fecundity" is used sensu Devlin and Stephenson 1987 , i.e., to denote the number of seeds produced via the female function). This species is characterized by broad variability in floral morphology, both within and among populations (Herrera 1988b, 1990a, $b$ ), and a previous study revealed a significant relationship between some elements of floral morphology and seed production of individual plants (steps 1 and 2 above) (Herrera 1990a). The investigation reported here was designed to cor- 


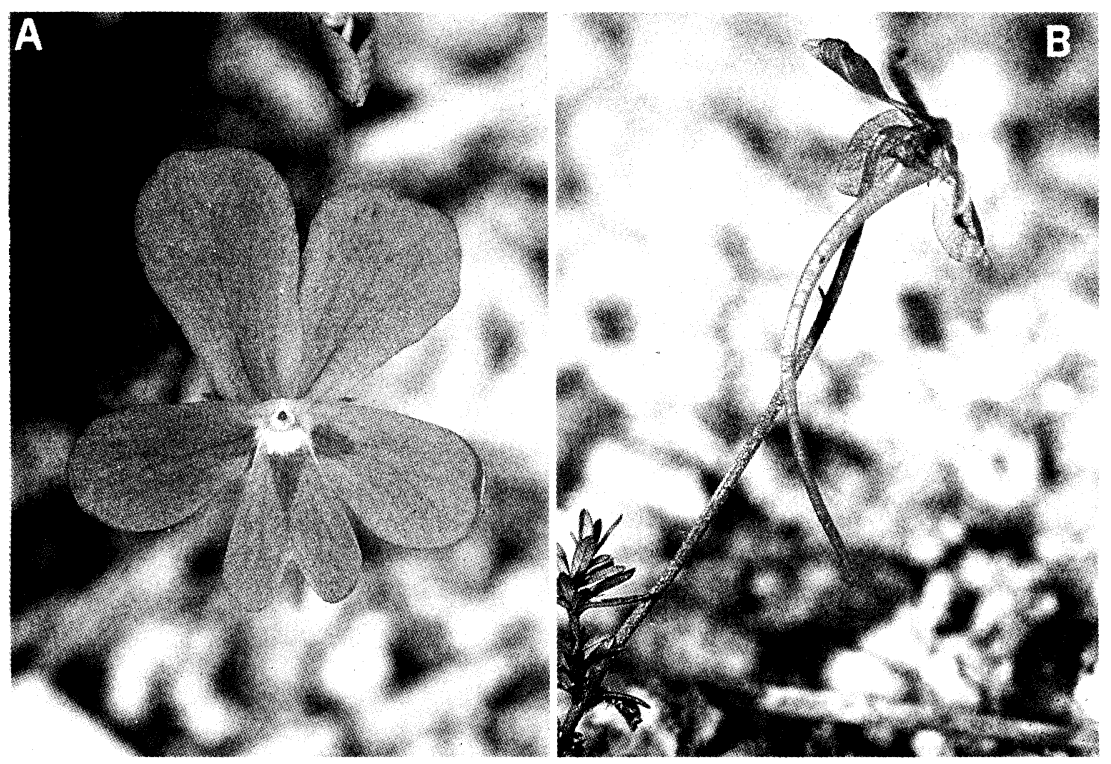

FIG. 1. Frontal (A) and side (B) views of a Viola cazorlensis flower.

roborate that relationship using data from more reproductive seasons, and to fulfill steps 3-5 above. The primary objective of this paper is thus to answer the question, What are the relative importances, as explanations of individual differences in fecundity, of variation in floral traits and of other fecundity determinants that are of an extrinsic nature, such as microhabitat type and interactions with herbivores? Relevant aspects of $V$. cazorlensis reproductive biology will be described, with special emphasis on the comparative effects of floral morphology, herbivory, and microhabitat type, on reproductive output at the individual plant level.

Results of this study will also be related to the following questions: (a) May the distinctive floral morphology of $V$. cazorlensis be interpreted as an adaptation to its present-day pollinators? In prominent contrast with the generality of Viola species studied to date (Valentine 1962, Veerman and van Zon 1965, Beattie 1969, 1971, 1972a, b, 1974), flowers of $V$. cazorlensis have a closed corolla with an extremely narrow entrance (Fig. 1 left), a very long spur (Fig. 1 right), and are pollinated almost exclusively by a single species of day-flying hawk moth (see Plant natural history below). The joint occurrence of morphological differentiation relative to congeneric species and virtual dependence on a single pollinator (monophily), might suggest the existence of pollinator-driven floral evolution in this species; (b) Do data for $V$. cazorlensis provide support for the prevailing paradigm on the evolution of highly "specialized" flowers with deep corolla tubes (Nilsson 1988)? The broad natural variability in spur length characteristic of this species will provide an opportunity to test for a positive relationship between corolla tube length and reproductive success, as found in other plants with long tubular corollas
(Nilsson 1988, Robertson and Wyatt 1990); and (c) Is corolla shape, independently of the size of flower parts, related to reproductive success? Previous investigations of phenotypic selection on floral morphology have considered either discontinuous (color, scent) or simple metric (size of flower parts) characters, but no quantitative studies exist on the influence of flower form on reproductive success. Nevertheless, some insect pollinators are able to discriminate among flower shapes (Anderson 1977, Gould 1985, 1986) and could thus induce shape-based differences in reproductive success (Levin 1969). In this study, both size of flower parts and shape of corolla outline will be examined for $V$. cazorlensis. To my knowledge, this is the first investigation examining quantitatively the possibility of phenotypic selection on flower shape.

\section{Plant Natural History}

Viola cazorlensis is a perennial, suffruticose violet endemic to two nearby limestone mountain ranges in southeastern Spain (Melchior and Cuatrecasas 1935, Gómez Campo 1987). This species, along with two closely related taxa occurring in the Balkan Peninsula ( $V$. delphinantha and $V$. kosaninii; Valentine et al. 1968), constitute the small section Delphiniopsis of the genus Viola, an old and apparently primitive lineage (Valentine 1962, Quézel et al. 1980). In the Sierra de Cazorla, where the present study was conducted (see Study site below), the species occurs as widely disjunct, isolated populations varying in size from a few dozen to, rarely, several thousand individuals (Herrera 1988b, $1990 \mathrm{~b}$ ). Populations are always associated with wellinsolated rocky outcrops, cliffs, or "islands" of limestone-derived, heavily weathered sandy soils (locally known as "arenales"), between 900 and 2100 m elevation. 
In winter, the aerial parts of $V$. cazorlensis plants are reduced to inconspicuous buds or small rosettes on the surface of the woody rootstock. Vegetative growth starts in early spring, involving rapid production of stems, leaves, and flower buds. In spring and early summer, plants have a loose, cushion-like appearance, and generally do not exceed $10-12 \mathrm{~cm}$ in height. Timing of flowering varies with elevation, but the flowering period generally extends from early May through midJune. Fruits (dehiscent capsules) mature within 3-4 wk of flowering. Seeds are small (mass $=1.2 \pm 0.25 \mathrm{mg}$ [mean $\pm 1 \mathrm{SD}$ ], $N=50$ ), lack special dispersal mechanisms (elaiosomes, frequent in Viola species, were never observed), and are myxospermous (they develop a conspicuous mucilaginous, sticky coat when soaked in water). Stems and leaves start to wither by late summer, becoming brown and senescent in autumn.

Flowers of $V$. cazorlensis are scentless (to the human nose), have pinkish-purple corollas, and are characterized by a long, thin spur (Fig. 1B) (length $=25.0 \pm$ $3.86 \mathrm{~mm}$ [mean $\pm 1 \mathrm{sD}$ ], range $8-42 \mathrm{~mm}, N=1089$ ), the longest of all European species in its genus (Valentine et al. 1968). The nectar, produced by two filiform nectaries, accumulates at the tip of the spur, and can be reached only by long-tongued insects (standing crop $=0.24 \pm 0.28 \mu \mathrm{L}, N=247$ flowers; concentration $=26.7 \pm 3.9 \%$ sucrose equivalents on a mass $/$ mass basis). No evidence of nectar robbing was ever observed. Pollination is accomplished virtually by a single insect species, the day-flying hawk moth Macroglossum stellatarum (Lepidoptera: Sphingidae), an unusual feature for the genus Viola (Beattie 1974). Floral visitors recorded during a total of $63 \mathrm{~h}$ of observation at the Cruz de Quique study site (see Study site below) over five flowering seasons (1987-1991) comprised $M$. stellatarum (47 observations), Hemaris tityus (Sphingidae; 1 observation), two species of bombyliid flies (Bombylius venosus and B. torquatus, 2 observations each), honey bees (Apis mellifera, 1 observation), and bumble bees (Bombus terrestris, Psithyrus vestalis; 1 observation each). Among these, only hawk moths and bombyliid flies actually probed the corolla with their mouthparts. $M$. stellatarum was responsible for $98.1 \%$ of all floral visits recorded ( $N=502$ flowers).

Although flowers of $V$. cazorlensis are self-compatible and may occasionally produce fruits in absence of pollinators, the activity of these is essential for fruit set (Herrera 1990a). Pollinators were infrequently seen in the study population $(0.81$ foraging individuals $/ \mathrm{h}$ on average, hawk moths and bombyliid flies combined), and flower visitation rates were accordingly very low. The relatively high fruit set levels achieved by the species (see Results: Reproduction: Fruit production below) despite this prevailing scarcity of pollinators may be explained by the long duration of individual flowers (mean $\pm 1 \mathrm{SD}=9.9 \pm 2.1 \mathrm{~d}$, range $=$ 5-14 d; $N=32$ flowers).

Several herbivores and seed predators, acting at dif- ferent stages of the reproductive cycle, have negative effects on the fecundity of $V$. cazorlensis plants. During the flowering period, flower buds and open flowers are eaten by penultimate and last instar larvae of the nymphalid butterfly Fabriciana adippe (Fabriciana hereafter). Fruits are often destroyed prior to maturation by mammalian ungulates browsing on the plants. At the study site, and in the period 1988-1991, red deer (Cervus elaphus) and, to a lesser degree, semiferal goats, were responsible for the majority of fruit losses to mammals. Larvae of the pyralid moth Heliothella wulfeniana (Heliothella hereafter) are sometimes found inside developing capsules. Inside each infested fruit only a single larva is found; it invariably feeds on and destroys all seeds before leaving the fruit to pupate in the ground.

\section{STUDY SiTE}

This study was conducted in the period 1987-1991 on a population of $V$. cazorlensis growing at $1290 \mathrm{~m}$ elevation in La Cruz de Quique, Sierra de Cazorla (Jaén province, southeastern Spain). The vegetation of the area is open pine (Pinus nigra and P. pinaster) forest with a sparse understory of Juniperus phoenicea treelets and a xerophytic shrub layer dominated by Echinospartum boissieri, Rosmarinus officinalis, Thymus orospedanus, and Fumana ericoides. The substrate of the site is a complex mosaic made up of large bare rocks at ground level, small cliffs (2-4 $\mathrm{m}$ in height), and pockets of loose, coarse-grained, limestone-derived sandy soils. $V$. cazorlensis plants occur on all substrate types, thus providing an opportunity for examining the influence on fecundity of easily recognizable microhabitat types (Herrera 1989). Three substrate categories were recognized for this study, namely pockets of sandy soil ("ground" hereafter), crevices of bare rocks at ground level ("rocks" hereafter), and crevices in vertical or overhanging cliffs $>2 \mathrm{~m}$ in height ("cliffs" hereafter).

\section{METHODS}

An area-based, extensive survey of the local population of V. cazorlensis at La Cruz de Quique was conducted in June 1987 and June 1988 to assess the proportional distribution of plants among substrate types, the size structure of the population, and the proportion of flowering individuals at the population level. All plants occurring within an area of $150 \times 50 \mathrm{~m}$ were measured (length of longest canopy axis), and scored for substrate type and flower production.

In April 1988, 75 plants were measured (length of longest canopy axis) and individually marked with permanent tags before the start of flowering in the population. These plants were studied in detail during four consecutive reproductive seasons (1988-1991), and have provided most of the data for this study. None 
of them died over the 4-yr study period. Plants were measured again at the end of the study in 1991, and none of them exhibited size variations with respect to initial measurements beyond estimated measuring error $( \pm 2 \mathrm{~cm})$. Some aspects of the reproduction of $V$. cazorlensis (flowering phenology, nectar production, and flower duration, among others; mentioned above under Plant natural history) were investigated during a pilot study conducted in 1987 on a subset of marked plants $(N=51)$. Supplementary data from that year will be included in the analyses of the frequency of flowering by individual plants. Data obtained during the area-based survey of the population will be used to determine whether the group of individually marked plants was a representative subset of the population in terms of substrate use and size structure.

Every reproductive season (roughly from late April through early July), all marked plants were examined regularly at 3-7 d intervals. During the flowering period, measurements were taken in the field on all ( 1988 and 1989), or a subsample thereof (1990 and 1991), the flowers produced by marked plants (see Floral morphology below). Each study season, the following information was obtained for all marked plants: total number of flowers produced, effect of the three main agents of herbivory (Fabriciana, Heliothella, and mammalian ungulates) on flower and fruit production, total number of successful capsules eventually produced, and mean number of filled seeds per capsule ("brood size" hereafter). All mature capsules produced (1988 and 1989), or a subsample of them (1990 and 1991), were collected shortly prior to dehiscence, examined under a dissecting microscope, and the number of seeds counted. Furthermore, the number of ovules that had failed to develop into seeds could be accurately counted for many of the capsules. By adding this figure to the number of filled seeds, I obtained the initial number of ovules in the flower that produced the capsule. Examination of capsules served also to determine the effect of the pyralid seed predator Heliothella on fruit production, as I was unable to recognize infestation by this species externally.

The impact of Fabriciana herbivory on the reproduction of individual $V$. cazorlensis plants was evaluated using the proportion of flowers and flower buds consumed in each reproductive episode. Infestation rate by Heliothella was calculated for each plant and season as the proportion of nearly mature fruits that contained (or had contained, as revealed by frass and remains of eaten seeds) larvae of this species. Unripe fruits lost to mammalian herbivores included not only fruits that would have eventually produced a successful capsule, but also an unknown proportion of Heliothel$l a$-infested fruits plus others that would perhaps have been aborted spontaneously by the plants prior to maturation. It was thus impractical to measure accurately the effect of vertebrates in terms of proportional reduction in fruit number. For this reason, the impact of vertebrates on the fruit production of individual plants was estimated indirectly by means of the proportion of the plant's surface that had been browsed by the time of fruit ripening (late June-early July). These figures will closely reflect the proportion of viable fruits lost to ungulates in a given reproductive season, provided that fruits tended to be evenly distributed over the plant surface, mammals browsed indiscriminately on vegetative and reproductive structures, and no evidence was ever recorded of short-term changes in plant architecture or compensatory fruit production induced by browsing (C. M. Herrera, personal observation).

\section{Artificial pollinations}

As virtually a single insect species ( $M$. stellatarum) is involved in the pollination of $V$. cazorlensis flowers, no possibility exists for individual plants to differ in any important way with regard to pollinator composition. Differences could still exist, however, in terms of frequency of visitation by the one pollinator. Nevertheless, the scarcity of $M$. stellatarum at the study site rendered impractical characterizing marked plants with respect to their interaction with the pollinator by means of direct observations in the field. For the purposes of the study, one valid, although indirect, way of overcoming this limitation is demonstrating that the possibility of differential pollinator behavior influencing individual variation in fecundity actually exists.

In 1989, pollinators were excluded from $15 \mathrm{~V} . \mathrm{ca}$ zorlensis plants (different from the marked ones used for monitoring flower and fruit production) by means of $0.3 \times 0.3 \times 0.3 \mathrm{~m}$ exclosures. Twelve exclosures were used, several of which covered more than one plant, and they were placed before any flower had opened on the experimental plants. Virgin flowers subsequently opening within the exclosures were handpollinated according to a factorial design. Flowers were pollinated with either own or cross pollen, and on one or two occasions (3-d interval). Given the scarcity of the hawk moth pollinator, the narrow range of pollination frequencies chosen was thought to reproduce realistically the natural pollination regime faced by $V$. cazorlensis flowers at the study population. As many pollination treatments as possible (depending on flower availability) were represented within single exclosures. Due to the complex internal architecture and pollination mechanism of $V$. cazorlensis flowers (C. M. Herrera, personal observation), hand-pollinations required the use of an artificial hawk moth proboscis. It was made of flexible nylon thread, and matched accurately the insect's proboscis in length, diameter, and degree of tapering toward the tip.

\section{Floral morphology}

Two complementary approaches were used to characterize the fioral morphology of marked plants. One of these involved the use of five "conventional," linear 
$\underline{A}$

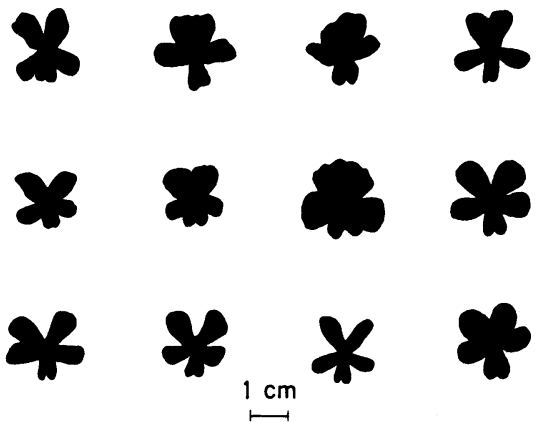

$\underline{B}$

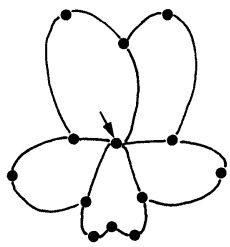

FIG. 2. (A) Corolla outline (front view) of selected Viola cazorlensis flowers from the study site, to illustrate the variability in corolla shape characteristic of this species. Outlines were traced directly from photographs. Each flower is from a different plant. (B) Idealized $V$. cazorlensis flower (front view), showing the location of landmarks used in the analysis of corolla shape (dots). The landmark marked by the arrow corresponds to the aperture of the corolla tube.

measurements of the size of flower parts (see Herrera 1990a: Fig. 1). Flowers of $V$. cazorlensis are produced singly on 15-95 mm long peduncles. Irrespective of the inclination of the substrate (from horizontal soil to vertical or overhanging cliffs), the five petal blades tend to fall in a nearly vertical plane (Fig. 1). Petals are thus designated here as "lower," "middle," and "upper." Maximum length of petal blades ("petal length" hereafter) was measured for the upper, middle, and lower petals. Measurements of the spur and the peduncle were taken after gently straightening these structures ("peduncle length" and "spur length" hereafter). In the period 1988-1991, measurements were taken in the field on a total of 1110 individual flowers from 62 marked plants (some plants did not flower during the course of the study).

Linear measurements of flower parts do not describe adequately the whole range of variability exhibited by $V$. cazorlensis flowers, particularly with respect to corolla shape. In front view, corollas are bilaterally symmetrical, but considerable variation exists in the shapes of their contours, due to differences in the outline and relative arrangement of petals (Fig. 2A). Corolla outlines range from fairly regular and unbroken shapes with shallow clefts between the petals, to markedly interrupted, star-like shapes with deep clefts. This variation could provide the basis for discrimination among flowers by the visually oriented pollinator $M$. stella- tarum (Knoll 1922), thus leading to differences in fecundity.

Variability in corolla shape was studied in 1991 on a sample of 229 flowers from 51 marked plants. Closeup photographs were taken from individual flowers in the field using a standardized procedure (front view, white cardboard as background, and linear scale and identification tag added for reference). To describe corolla shape and the relative position of the aperture of the corolla tube, I selected 13 "landmarks" (Bookstein $1990 a$, Rohlf 1990b) located on the surface of the plane determined by petal blades (Fig. 2B). Except for the aperture of the corolla tube, all landmarks were located on the contour of the corolla plane as seen in front view (petal tips, points of juxtaposition of contiguous petals, and the innermost point of the lower petal's notch). For each photographed flower, $X-Y$ coordinates of landmarks were obtained with a computer from digitized flower images. Flower images were obtained by scanning black-and-white photographic prints using a Hewlett-Packard Scanjet Plus page scanner.

\section{Data analysis}

Most analyses in this paper were performed using procedures in the SAS statistical package (SAS 1988). Analyses of variance and covariance were done with procedure GLM and Type III sum of squares, and variance components were obtained using procedure VARCOMP. Parametric regression was used to estimate the effects of floral morphology on plant fecundity, and nonparametric regression (cubic splines; Schluter 1988) was applied to evaluate the shape of selection functions on floral traits. The comparative influence of floral morphology and environmental factors on fecundity were examined using path analysis. Details of these procedures are mentioned at appropriate places in Results.

Bookstein's $(1990 b, 1992)$ method of thin-plate splines relative warps (TPSRW) analysis was used to examine variation in corolla shape (program TPSRW, version 18 November 1991, written by F. James Rohlf). This landmark-based morphometric procedure identifies successive, independent trends of nonuniform shape change in order of decreasing overall importance, from more general to more localized features of shape. Scores are then obtained for each object on each relative warp. Relative warps can be thought of as the principal component axes of a multivariate space in which each point corresponds to a specimen (one individual flower in the present study), and the axes are the inversely weighted principal warps of the bending energy matrix defined by a reference configuration of landmarks. Relative warps analysis represents the principal components analysis of the nonlinear part of a sample of forms. Detailed accounts of the theoretical foundations, analytical methods involved, and applications of TPSRW analysis may be found in Bookstein (1990b, 1992), Johnston et al. (1991), and Rohlf (in 
press). Prior to performing TPSRW analysis, landmark configurations of individual flowers were all aligned with respect to a consensus configuration, using a generalized rotational (Procrustes; Goodall 1991) method (generalized resistant fit, as described by Rohlf and Slice 1990) using program GRF (version 12 September 1991) written by F. J. Rohlf and D. Slice (Rohlf 1990a).

Throughout this paper, means are shown \pm 1 sD unless otherwise indicated, and $N$ denotes sample size.

\section{RESULTS}

\section{Substrate use and population structure}

A total of $790 \mathrm{~V}$. cazorlensis plants were examined in the 1987-1988 area-based survey of the study population, $36.5 \%$ of which were growing on the ground, $43.2 \%$ on rocks, and $20.3 \%$ on cliffs. Plants on the three substrates differed slightly in mean size (longest canopy axis). On average, cliff plants tended to be the largest $(13.9 \pm 7.8 \mathrm{~cm}, N=160)$, rock plants the smallest $(11.9 \pm 6.2 \mathrm{~cm}, N=342)$, and ground plants intermediate $(13.0 \pm 7.5 \mathrm{~cm}, N=288)$. These differences are at best only marginally significant $(F=2.76, \mathrm{df}=$ $2,787, P=.064$; data $\log$ transformed for the analysis), and there was complete overlap between substrate classes in the distribution of plant size (Fig. 3).

The 75 marked plants studied in detail during 19881991 are a representative subset of the population with regard to substrate use and size structure. The proportional distribution of individuals among substrate types in the marked group did not differ from that for the population $(G=0.32, \mathrm{df}=2, P=.85)$. Furthermore, differences in mean plant size among substrates were similar to those found for the population as a whole (cliff plants: $15.4 \pm 5.6 \mathrm{~cm}, N=14$; rock plants: $11.2 \pm 4.7 \mathrm{~cm}, N=35$; ground plants: $14.8 \pm 5.8 \mathrm{~cm}$, $N=26 ; F=4.17, \mathrm{df}=2,72, P=.019, \log$-transformed data).

\section{Reproduction}

Frequency of flowering. - Only a fraction of the $V$. cazorlensis population flowered in any one year. Among the plants examined during the 1987-1988 area-based survey, only $65.3 \%$ had flowered in the current season. Flowering individuals occurred significantly more often in the largest size classes (59.0 and $72.6 \%$ for plants below and above the median size for the population, respectively; $G=14.16, \mathrm{df}=1, P<.001$ ), but they were represented in all size classes in the three substrate types (Fig. 3). There was no apparent size threshold for flowering, as reproductive individuals were frequent even in the smallest size class $(<5 \mathrm{~cm})$ (Fig. 3).

The interannual pattern of flowering of individuals could be studied in detail in the set of marked plants. Among these, the proportion of flowering individuals varied significantly between years $(G=16.9, \mathrm{df}=4$, $P=.002)$, ranging from $56 \%(1989)$ to $82.7 \%$ (1991) (Table 1A). This magnitude was directly correlated with

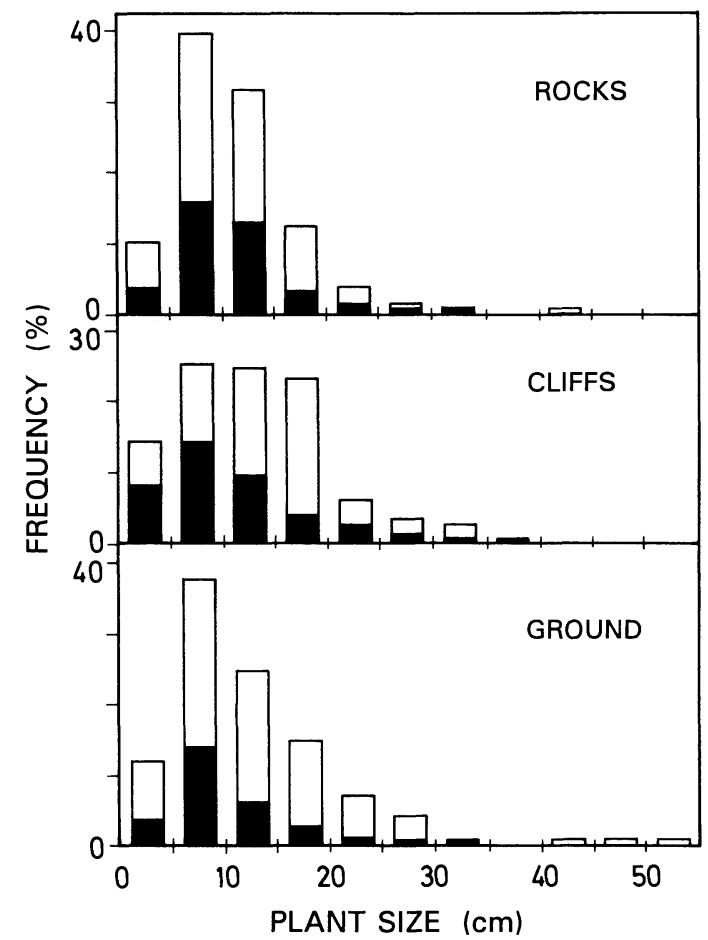

FIG. 3. Frequency distributions of plant size (length of longest canopy axis) in the three substrate types, based on the area-based survey of the study population conducted in 19871988. The filled portion of bars corresponds to individuals not flowering, and the open portion to individuals flowering during the current season $(N=279,147$, and 255 plants, for rocks, cliffs, and ground, respectively; only plants without signs of ungulate browsing were included).

TABLE 1. Flowering frequency of marked Viola cazorlensis plants in the period 1987-1991. $N=$ number of plants examined on a given year (A) or substrate type (B).

\begin{tabular}{cllllll}
\hline \hline \multicolumn{6}{c}{ A) Annual variation in the proportion of plants flowering. } \\
& $1987^{*}$ & 1988 & 1989 & 1990 & 1991 \\
\hline $\begin{array}{c}\text { Percent of plants } \\
\text { flowering }\end{array}$ & 70.0 & 60.0 & 56.0 & 58.7 & 82.7 \\
$N$ & 51 & 75 & 75 & 75 & 75
\end{tabular}

B) Frequency of flowering of individual plants in the 19881991 period. $\dagger$

Number

\begin{tabular}{|c|c|c|c|c|}
\hline \multirow{2}{*}{$\begin{array}{l}\text { of years } \\
\text { flower- } \\
\text { ing }\end{array}$} & \multicolumn{4}{|c|}{ Substrate type } \\
\hline & Rocks & Cliffs & Ground & Total \\
\hline $\begin{array}{l}0 \\
1 \\
2 \\
3 \\
4 \\
5\end{array}$ & $\begin{array}{r}17.1(11.4) \\
25.7(17.1) \\
11.4(17.1) \\
28.7(14.3) \\
17.1(22.9) \\
(17.1)\end{array}$ & $\begin{array}{l}7.1 \\
0 \\
7.1 \\
21.4 \\
64.4\end{array}$ & $\begin{array}{r}11.5(18.2) \\
7.7(9.1) \\
15.4(9.1) \\
11.5(27.3) \\
53.9(18.2) \\
\quad(18.2)\end{array}$ & $\begin{array}{r}13.3(9.8) \\
14.7(17.6) \\
12.0(15.7) \\
21.3(15.7) \\
38.7(25.5) \\
\quad(15.7)\end{array}$ \\
\hline$N$ & $35 \quad(35)$ & 14 & $26 \quad(11)$ & $75 \quad(51)$ \\
\hline
\end{tabular}

* Plants surveyed in 1987 were a subset of those studied over 1988-1991.

$\dagger$ In parentheses, figures obtained separately for the subset of plants that were surveyed over 1987-1991 (few of these were growing in cliffs, and separate data are not shown for this substrate type). 


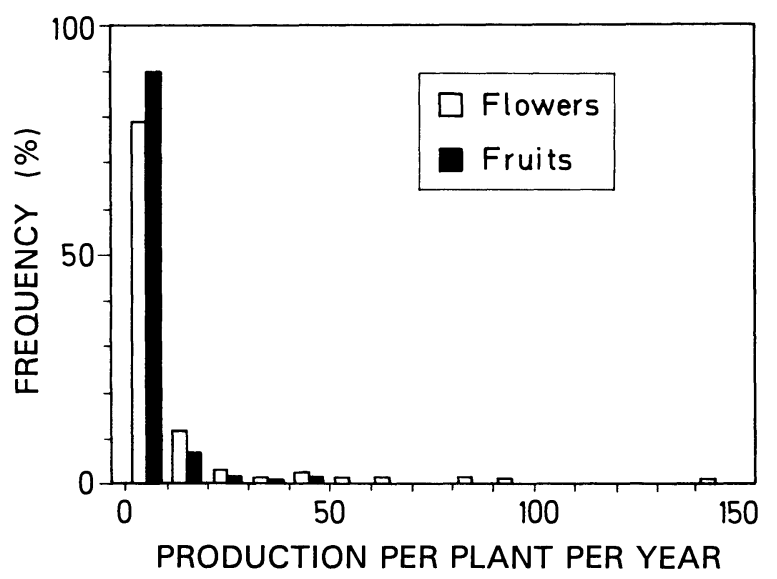

FIG. 4. Frequency distributions of flower and fruit production (per plant and season) by marked Viola cazorlensis plants in the period 1988-1991, all plants and years combined. Only data for actual flowering events were included (i.e., 0 flowers $\cdot$ plant $^{-1}$ ' season $^{-1}$ figures are excluded).

the cumulative rainfall in the 3 mo immediately preceding flower differentiation (January-March), although there are few data points and the correlation coefficient is not significant (Spearman rank correlation, $r_{s}=0.800, N=5 \mathrm{yr}, P=.10$ ).

The full range of supra-annual flowering frequencies was represented among marked plants, from individuals flowering every year to those that did not produce any flower over five consecutive seasons (Table 1B). Most plants failed to flower on one year or another, and only a relatively small proportion of individuals flowered every year. The frequency of flowering of individual plants varied among substrates (Table 1B). Over the 1988-1991 period, plants growing on rocks, ground, and cliffs flowered on an average of 2.0, 2.9, and 3.4 occasions, respectively, and differences among substrates are statistically significant $(F=3.58$, df $=$ $2,72, P=.032$; frequency data square root transformed for the analysis). Nevertheless, when plant size (log transformed) was included in the analysis as a covariate, the effect of substrate type on flowering frequency vanished $(F=0.16, \mathrm{df}=2,69, P=.85)$, and size became the only significant effect $(F=13.47$, df $=1,69, P=.0005$ ). Frequency of flowering thus depended on plant size, and differences among substrate types in that magnitude were apparently only an incidental consequence of differential plant size.

Flower production. - During flowering years, most $V$. cazorlensis plants produced only a few flowers. In the 1987-1988 survey of the population, $92.5 \%$ of flowering individuals $(N=388)$ produced $\leq 10$ flowers in the current season, and $78.1 \%$ of plants produced $\leq 5$ flowers.

In the set of marked plants, flower production was $\leq 10$ flowers $\cdot$ plant $^{-1}$. season $^{-1}$ in $78 \%$ of instances $(N$ $=192$ plant-seasons, all plants and years combined; zero production figures were excluded to deal exclu- sively with actual reproductive episodes) (Fig. 4). Only a few individuals produced $>50$ flowers per season. There was significant consistency among years in the rank order of individuals with regard to flower production. Yearly flower production for individual plants was positively correlated across years in the six possible pairwise combinations $\left(r_{s}\right.$ range $=0.550-0.789, N=$ $75, P \ll .001$ in all cases).

Mean flower production per plant varied significantly among years $(F=3.89, \mathrm{df}=3,180, P=.010)$ and substrate types $(F=12.60, \mathrm{df}=2,180, P<.0001)$ (two-way ANOVA with interaction, substrate type, and year as main effects; flower production log transformed for the analysis). Substrate type accounted for a greater proportion of total variance in flower production $(14.4 \%)$ than annual variation $(4.1 \%)$. When they flowered, rock plants produced significantly fewer flowers per season $(5.0 \pm 7.2)$ than either cliff $(13.9 \pm 26.8)$ or ground (13.4 \pm 19.1$)$ ones. Differences between substrates remained consistent among years, as indicated by the nonsignificance of the interaction term in the ANOVA $(F=1.29, \mathrm{df}=6,180, P=.26)$. The effect of substrate type on flower production remained significant after including plant size (log transformed) in the analysis as a covariate $(F=3.51, \mathrm{df}=2,179, P=$ .032).

Plants producing the most flowers during each reproductive event tended also to be those flowering with the greatest supra-annual frequency (Fig. 5). The number of flowering events of individual plants over 19881991 (square-root transformed) was closely correlated with the mean number of flowers produced per flowering event (log transformed) $(r=0.753, N=64, P \ll$ .001 ; only plants flowering at least once included). This correlation remains significant after partialling both variables on plant size (log transformed) and substrate type (coded using two dummy variables; Pedhazur 1982) (partial $r=0.673, P \ll .001$ ), demonstrating that the relationship between flowering frequency and flower production is not an artifact resulting from indirect correlations with size or substrate type.

Fruit production. - Fruit production per plant and season was very low. In the 1987-1988 survey of the population, $96.9 \%$ of individuals that had flowered during the current season $(N=388)$ produced $\leq 10$ fruits, and $87.4 \%$ produced $\leq 5$ fruits (only plants unaffected by ungulates were included in the analysis).

Among marked plants, fruit production was $\leq 10$ fruits $\cdot$ plant $^{-1} \cdot$ season $^{-1}$ in $90 \%$ of instances, with a few individuals producing $>20$ fruits per season (Fig. 4). There was significant consistency among years in the rank order of individuals with regard to fruit production. Yearly fruit production for individual plants was positively correlated across years in the six possible pairwise combinations $\left(r_{s}\right.$ range $=0.486-0.717, N=$ $75, P \ll .001$ in all cases).

Variation among substrates and years in fruit production was analogous to that reported above for flower 


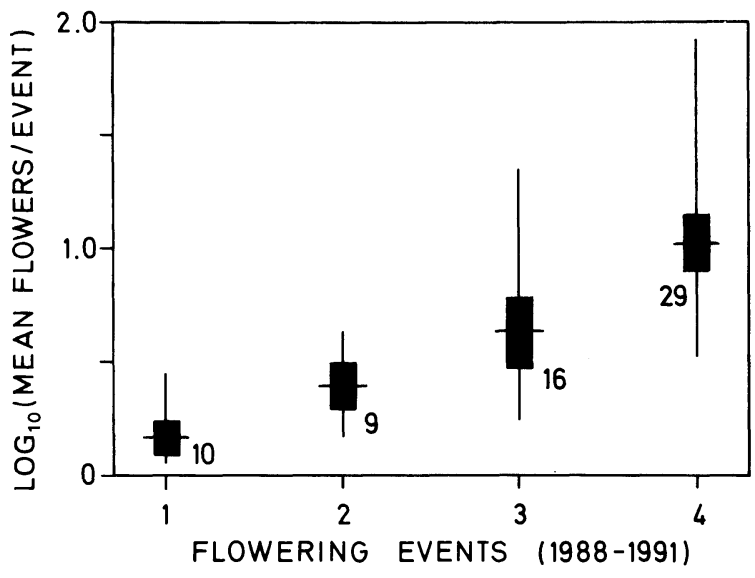

FIG. 5. Relationship between mean flower production per flowering event and number of flowering events in the period 1988-1991, for individually marked piants. Boxes extend \pm 2 SE around the mean (horizontal line), vertical lines correspond to the observed range, and numbers beside boxes are sample sizes for each flowering frequency class.

production. There was significant heterogeneity in mean fruit production among substrates $(F=24.15$, df $=2$, $180, P<.0001)$ and among years $(F=3.94$, df $=3$, $180, P=.01)$, and differences between substrates remained consistent between years (interaction term in the ANOVA: $F=1.02$, df $=6,180, P=.41$ ) (number of fruits $\log$ transformed for the analysis). The effect of substrate accounted for $20.3 \%$ of variance in fruit production, while annual variation accounted only for $5.5 \%$. For all years combined, number of fruits per plant per season increased from rock-growing (2.5 \pm
4.0 plants $)$ through ground-growing $(4.7 \pm 6.9$ plants $)$ to cliff-growing individuals $(8.7 \pm 11.2$ plants $)$.

Variation among substrates in mean fruit production per plant does not match the gradient in mean flower production described in the preceding section (Flower production), indicating that the proportion of flowers that produced mature capsules differed among substrate types. The slopes of the regressions of fruit number on flower number (both log transformed) obtained separately for the three substrate types (Fig. 6; all years combined) do not differ significantly $(F=1.34$, $\mathrm{df}=$ $2,186, P=.27)$, but the least squares-adjusted means (with respect to flower production) are significantly heterogeneous $(F=20.58, \mathrm{df}=2,186, P<.0001)$ (analysis of covariance). Holding the number of flowers constant, plants on cliffs tended to produce more fruits than those on either rocks or ground (Fig. 6). Adjusted means ( $\pm 1 \mathrm{SE}$ ) for ground-, rock- and cliff-growing plants were, respectively, $3.7 \pm 0.5,4.3 \pm 0.5$, and $7.5 \pm 0.6$ fruits plant $^{-1} \cdot$ season $^{-1}$.

Variation among substrates in fruit production may be caused by differences in the proportion of flowers leading to developing fruits (fruit set), proportional losses of flowers and fruits to herbivores, or both. The effect of herbivores will be analyzed below (Interactions with animals: Herbivores and seed predators). Possible differences in potential fruit set may be examined using the same data represented in Fig. 6 after removal of all instances (plant - season) where some flowers or fruits were lost to herbivores. In this reduced data set made up exclusively of "herbivory-free" plants, differences between substrates in fruit set are no longer significant ( $F=0.84, \mathrm{df}=2,234, P=.43)$, demonstrating that

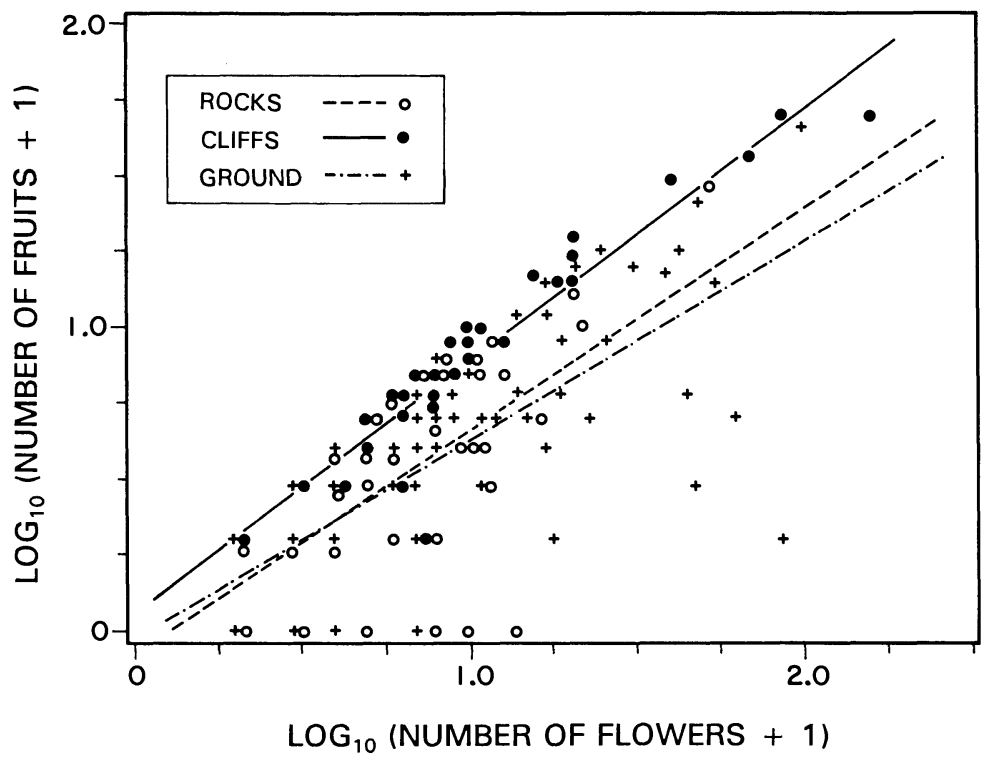

FIG. 6. Realized fruit set (number of successful fruits per plant per season) of marked Viola cazorlensis plants in relation to flower production (flowers per plant per season), all plants and years combined. Each symbol corresponds to a single plant in a particular year, coded according to substrate type. Separate regression lines (least squared fitted) are shown for the three substrate types (see Results: Reproduction: Fruit production for results of analysis of covariance). 
TABLE 2. Summary of mixed-model analysis of variance for the effects of substrate type, plant, and number of ovules, on the number of seeds of Viola cazorlensis fruits $(N=389$ fruits). Plants were nested within substrates, and treated as random effects. The initial number of ovules in the ovary was treated as a covariate.

\begin{tabular}{lccl}
\hline \hline \multicolumn{1}{c}{ Effect } & $F$ & $\mathrm{df}$ & \multicolumn{1}{c}{$P$} \\
\hline Substrate & 0.58 & 2,38 & .56 \\
Plant (within Substrate) & 0.93 & 38,291 & .60 \\
Ovules & 8.55 & 1,291 & .004 \\
Ovules $\times$ Substrate & 0.50 & 2,291 & .61 \\
Ovules $\times$ Plant (within Substrate) & 1.00 & 12,291 & .47 \\
\hline
\end{tabular}

plants growing in different microhabitats do not differ in potential fruit set levels.

Plants flowering in more than one season occur multiple times in the data set for all years combined, and this circumstance could have introduced some biases in the preceding analyses. To rule out this possibility, separate analyses of covariance were conducted for each study season (results not shown). Homogeneity of fruits vs. flowers regression slopes, and statistical significance of differences in the adjusted means of fruit production among substrate types, were confirmed for each of the four study seasons (see also Herrera 1989 for an independent analysis of the substrate-dependence of fruit and flower production in $V$. cazorlensis with similar results).

Brood size. - Mature capsules varied broadly in seed number ("brood size"). For all plants and years combined, fruits had an average of $10.0 \pm 5.1$ seeds (range $=1-30$ seeds; $N=642$ fruits from 64 plants). Variation in brood size was examined using a mixed-model analysis of variance, treating substrate type as a fixed effect, and plant and year as random effects. Plants were nested within substrate types. Variation among plants in brood size was highly significant $(F=5.15$, df $=56$, $601, P<.0001)$. No significant heterogeneity was found among either years $(F=2.09, \mathrm{df}=3,601, P=.10)$ or substrate types $(F=0.12, \mathrm{df}=2,56, P=.89)$.

Extensive within-ovary brood reduction takes place in $V$. cazorlensis. The initial number of ovules was determined in a subsample of the mature fruits examined. Mean number of ovules per ovary was 23.9 \pm 5.9 (range $=11-55, N=389$ ), or about twice the mean number of filled seeds per fruit. Individual variation in mean brood size could thus be due to variation in the mean number of ovules per ovary, extent of brood reduction, or both. Furthermore, the magnitude of brood reduction might vary among substrate types. These hypotheses were examined using a mixed-model analysis of variance (Table 2). After accounting for variation in the number of ovules, differences between plants in brood size were no longer significant. The extent of brood reduction (relationship between the numbers of ovules and seeds) did not differ among substrates or among plants within substrates. Individual variation in mean brood size thus mainly reflected differences in the number of ovules per ovary, not differential levels of brood reduction.

\section{Interactions with animals}

The fecundity of $V$. cazorlensis plants depends in several ways on their interactions with animals. Fruit production requires the concourse of pollinators, and the number of fruits eventually matured by a plant will depend on the combined impact of Fabriciana, Heliothella, and ungulates on flowers and fruits. This section documents the effect of herbivores on fecundity, and presents indirect evidence on the potential influence of pollinators on seed production.

Herbivores and seed predators. - Estimates of the impact of herbivores and seed predators on the reproduction of $V$. cazorlensis plants were obtained by computing for each individual the percentage of flowers (Fabriciana) or fruits (Heliothella and ungulates) eaten by each herbivore in each study season. Herbivory estimates over four consecutive seasons are available for some plants, hence repeated-measures ANOVA using plants as subjects and years as the within-subject effect would formally be the most appropriate procedure for testing the significance of the effect of substrate type on the impact of herbivores. Nevertheless, using this method would entail a drastic reduction of sample sizes, as only 29 plants reproduced in all of the four study years and thus had an uninterrupted record of herbivory estimates. To take advantage of the entire data set (64 plants flowering one or more times over 1988-1991), I instead applied two-way ANOVAs with interaction using Year and Substrate as the main effects, even though this procedure admittedly has the disadvantage that plants flowering more often are overrepresented in the sample relative to those flowering infrequently (in the present data set, repeated-measures ANOVA would not be entirely free of this potential source of bias either, insofar as only a relatively small fraction of the population could enter the analyses).

Despite being taxonomically and behaviorally unrelated, the three herbivores were similar in causing the greatest average reproductive losses to plants growing on the ground, and this pattern remained unchanged during the four study seasons (Table 3). Differences among substrate types in mean impact were statistically significant for each of the three herbivores (Table 4). The Year $\times$ Substrate interaction was not significant for any of the three herbivores, indicating that differences among substrate types remained consistent among years. Only the impact of Heliothella varied significantly among years. As plants on different substrates do not differ in potential fruit set (see $R e$ production: Fruit production above), variation among substrate types in the impact of herbivores explains the observed differences in the proportion of flowers leading to successful fruits. For a given number of flowers, plants growing on either cliffs or rocks tend to produce more fruits than plants on the ground (Fig. 6) because 
TABLE 3. Variation among years and substrate types in the impact of herbivores on the reproduction of Viola cazorlensis plants. Entries are percentages (mean $\pm 1 \mathrm{SD}$ ), on a per plant basis, of flowers (Fabriciana) or fruits (Heliothella and ungulates) eaten each season. ${ }^{*} N=$ number of plants.

\begin{tabular}{cllccc}
\hline \hline Year & Substrate & $N$ & Fabriciana & Heliothella & Ungulates \\
\hline \multirow{2}{*}{1988} & Rocks & 14 & 0 & $7.1 \pm 26.7$ & 0 \\
& Cliffs & 10 & 0 & $2.3 \pm 6.3$ & $5.0 \pm 15.8$ \\
& Ground & 21 & $\mathbf{8 . 3} \pm \mathbf{1 7 . 7}$ & $\mathbf{1 3 . 4} \pm \mathbf{3 0 . 2}$ & $\mathbf{7 . 1} \pm \mathbf{2 1 . 2}$ \\
1989 & Rocks & 15 & 0 & 0 & $6.7 \pm 25.8$ \\
& Cliffs & 12 & $1.2 \pm 3.6$ & $0.2 \pm 0.8$ & 0 \\
1990 & Ground & 15 & $\mathbf{1 5 . 5} \pm \mathbf{3 4 . 7}$ & $\mathbf{2 . 7} \pm \mathbf{7 . 5}$ & 0 \\
& Rocks & 16 & $1.3 \pm 5.0$ & 0 & $\mathbf{1 5 . 0} \pm \mathbf{2 8 . 0}$ \\
& Cliffs & 12 & $2.8 \pm 9.6$ & $\mathbf{3 . 1} \pm \mathbf{1 2 . 5}$ & $\mathbf{2 5 . 0} \pm \mathbf{3 9 . 8}$ \\
& Ground & 16 & $\mathbf{1 5 . 2} \pm \mathbf{3 4 . 2}$ & $4.9 \pm 15.1$ & $1.1 \pm 5.9$ \\
& Rocks & 26 & $4.1 \pm 19.6$ & $\mathbf{4 . 9} \pm 9.6$ & 0 \\
& Cliffs & 13 & $0.1 \pm 0.3$ & $\mathbf{7 . 4} \pm \mathbf{1 0 . 9}$ & $\mathbf{1 4 . 5} \pm \mathbf{3 0 . 9}$ \\
\hline
\end{tabular}

* Only plants flowering in a given year were included in the computations. In all years, the three herbivores caused the greatest mean impact on ground-growing plants (entries shown in bold type).

of the greater losses to herbivores in this latter substrate.

Pollination. - For reasons described earlier (see Methods: Artificial pollinations), it was impractical to characterize individual plants with respect to their interaction with pollinators. One indirect way to overcome this limitation is to demonstrate at least that differential visitation rates by pollinators, if they occurred, might translate into differences in fecundity. This section presents the results of experimental pollinations aimed at determining the effects of pollen source (self vs. cross) and pollination frequency (once vs. twice, mimicking differential pollinator visitation rate) on fecundity.

The response of fruit set to experimental treatments was examined using a saturated linear model based on logistic regression (SAS procedure CATMOD; SAS 1988) (Table 5). Due to the reduced number of flowers per treatment in most experimental plants, Treatment $\times$ Plant effects could not be included in the model. There was no significant effect of pollen source on the probability of fruit set by individual flowers. Number of pollinations did have a significant effect on fruit set, irrespective of pollen source (nonsignificant interaction effect). Fruit set of flowers pollinated twice $(52.0 \%)$ almost doubled that of those pollinated only once (29.6\%) (control, unpollinated flowers within the same exclosures had a spontaneous fruit set of $1.1 \% ; N=$ 94). Among the fruits produced, the number of seeds per fruit was unrelated to either type of pollen $(F=$ 0.002 , $\mathrm{df}=1,69, P=.96$ ) or number of pollinations $(F=1.85$, df $=1,69, P=.18)$. Results were likewise nonsignificant when the number of filled seeds was expressed as a proportion of the original numbers of ovules in the ovary $(F=0.002, \mathrm{df}=1,62, P=.96 ; F$ $=0.02, \mathrm{df}=1,62, P=.89$; for type of pollen and number of pollinations treatments, respectively; data arcsine transformed for the analyses). It may then be concluded that differences between plants in visitation rate by the single pollinator species, if they occur, may determine variations in fecundity via modifications of fruit set.

\section{Floral morphology}

This section first describes patterns of individual variation in floral morphology (size and shape components), and then its correlates in terms of differential fecundity (seed production).

Size of flower parts. - The effects of substrate type, year, and individual variation on size of flower parts (petals, peduncle, spur) were examined using univariate mixed-model ANOVAs (Table 6). No significant effect of substrate type was found for any of the flower parts considered. There was significant individual variation in the mean size of all flower parts. Coefficients of variation of individual plant means were large, ranging from $10.0 \%$ for lateral petal length to $23.3 \%$ for peduncle length (Table 7). Significant annual variation

TABLE 4. Summary of two-way analyses of variance for the effects of year and substrate type (rocks, cliffs, and ground) on the impact of herbivores on the flowers (Fabriciana) and fruits (Heliothella, ungulates) of Viola cazorlensis plants (Table 3). Data were log transformed for the analyses.

\begin{tabular}{|c|c|c|c|c|c|c|}
\hline \multirow[b]{2}{*}{ Source } & \multicolumn{2}{|c|}{ Fabriciana } & \multicolumn{2}{|c|}{ Heliothella } & \multicolumn{2}{|c|}{ Ungulates } \\
\hline & $F$ & $P$ & $F$ & $P$ & $F$ & $P$ \\
\hline Substrate & 9.37 & $<.0001$ & 3.62 & .028 & 11.29 & $<.0001$ \\
\hline Year & 0.51 & .68 & 3.92 & .0097 & 0.18 & .91 \\
\hline Substrate $\times$ Year & 0.60 & .73 & 0.17 & .98 & 0.82 & .55 \\
\hline
\end{tabular}


TABLE 5. Analysis of variance table of the saturated linear model (based on logistic regression) for the effects of pollen source (self vs. cross pollination) and number of pollinations (one vs. two times) on the probability of fruit set by hand-pollinated flowers of Viola cazorlensis within exclosures ( $N=228$ flowers from 15 plants). The analysis was performed using procedure CATMOD in SAS (SAS 1988).

\begin{tabular}{lccc}
\hline \hline \multicolumn{1}{c}{ Source } & $\mathrm{df}$ & $\chi^{2}$ & $P$ \\
\hline Intercept & 1 & 3.40 & .065 \\
Pollen source $(\mathrm{P})$ & 1 & 0.01 & .932 \\
Number of pollinations (N) & 1 & 4.85 & .028 \\
$\mathrm{P} \times \mathrm{N}$ & 1 & 0.07 & .785 \\
\hline
\end{tabular}

occurred in the size of three flower parts (petals), and the Plant $\times$ Year interaction effect was also significant in four instances. Despite the statistical significance of these effects, however, the proportion of variance accounted for by them was comparatively minor in relation to the variance explained by individual differences, that represents the most important source of variation in size of flower parts (Table 6). Furthermore, one-way ANOVAs for the effect of plant on size of flower parts, all years and substrates combined (results not shown), indicate that among-plant variation was significantly greater than within-plant variation for all floral measurements. These observations provide justification for combining flower measurements from all study years into a single sample for each plant.

To reduce the number of descriptive variables, a principal components analysis (PCA) was performed on the correlation matrix of the five floral measurements, based on the 4-yr means of individual plants. The analysis revealed three major independent trends of variation across individuals in the size of flower parts (Table 8), involving the size of the petals (PC1), spur (PC2), and peduncle (PC3). Scores of individual plants on these three principal components will be used
TABLE 7. Summary of variation in mean size (length) of flower parts of $N=53$ marked Viola cazorlensis plants. Means were computed separately for each plant using data from all study years (plants with data from $<3$ flowers were excluded). $\mathrm{CV}=$ coefficient of variation of individual plant means.

\begin{tabular}{lccc}
\hline \hline & \multicolumn{2}{c}{ Length of flower part $(\mathrm{mm})$} & \multicolumn{2}{c}{$\mathrm{CV}$} \\
\cline { 2 - 3 } Flower part & Range & Mean $\pm 1 \mathrm{SD}$ & $(\%)$ \\
\hline Peduncle & $26.8-76.1$ & $43.9 \pm 10.25$ & 23.3 \\
Spur & $19.8-37.0$ & $25.5 \pm 3.25$ & 12.7 \\
Upper petal & $9.2-15.8$ & $12.3 \pm 1.27$ & 10.4 \\
Middle petal & $7.6-13.0$ & $9.9 \pm 0.99$ & 10.0 \\
Lower petal & $6.2-10.6$ & $7.8 \pm 0.94$ & 12.0 \\
\hline
\end{tabular}

to characterize them from the viewpoint of the size of flower parts (see Floral morphology and fecundity below).

Corolla shape. - Patterns of shape variation represented by the first two relative warps (RW1 and RW2) resulting from the TPSRW analysis of the sample of $229 \mathrm{~V}$. cazorlensis flowers photographed in 1991 are illustrated in Fig. 7 as thin-plate splines. Changes in shape associated with each relative warp are shown as deformations of an initial orthogonal grid superimposed on the average (consensus) configuration of landmarks on the $X-Y$ plane. RW1 is mainly related to variation in corolla shape brought about by changes in the relative disposition of the two upper and two lateral petals. RW2, in contrast, reflects variation in the relative size and disposition of the upper and lower petals, and in the situation of the aperture of the corolla tube relative to the tips of upper and lower petals (degree of eccentricity of that aperture along the vertical bilateral symmetry axis). Scores of individual flowers on RW1 and RW2 are shown in Fig. 7 to illustrate the range of variation in corolla shape represented in the sample studied.

TABLE 6. Summary of mixed-model univariate ANOVAs testing the effects of substrate type ("Substrate" effect; ground, rocks, and cliffs), annual variation ("Year" effect, $N=4 \mathrm{yr}$ ), and individual variation ("Plant" effect, $N=63$ plants), on the size of flower parts in Viola cazorlensis $(N=1078$ flowers for all plants and years combined). To improve presentation, proportions of variance accounted for are shown only for statistically significant $(P<.05)$ effects $(F$ values shown in bold type).*

\begin{tabular}{|c|c|c|c|c|c|}
\hline \multirow[b]{2}{*}{$\begin{array}{l}\text { Dependent } \\
\text { variable }\end{array}$} & & \multicolumn{4}{|c|}{ Source of variation } \\
\hline & & Substrate & $\begin{array}{c}\text { Plant } \\
\text { (Substrate) }\end{array}$ & Year & $\begin{array}{c}\text { Plant } \times \text { Year } \\
\quad \text { (Substrate) }\end{array}$ \\
\hline Peduncle length & $\begin{array}{l}F \text { value } \\
\% \text { variance }\end{array}$ & 2.9 & $\begin{array}{l}23.5 \\
62.9\end{array}$ & 3.1 & $\begin{array}{l}1.8 \\
0\end{array}$ \\
\hline Spur length & $\begin{array}{l}F \text { value } \\
\% \text { variance }\end{array}$ & 0.6 & $\begin{array}{r}8.0 \\
33.4\end{array}$ & 0.2 & $\begin{array}{l}2.9 \\
9.8\end{array}$ \\
\hline Upper petal length & $\begin{array}{l}F \text { value } \\
\% \text { variance }\end{array}$ & 1.1 & $\begin{array}{r}7.7 \\
41.4\end{array}$ & $\begin{array}{l}9.7 \\
6.4\end{array}$ & $\begin{array}{l}1.6 \\
0\end{array}$ \\
\hline Middle petal length & $\begin{array}{l}F \text { value } \\
\% \text { variance }\end{array}$ & 2.1 & $\begin{array}{r}6.5 \\
38.0\end{array}$ & $\begin{array}{r}12.5 \\
9.7\end{array}$ & 1.3 \\
\hline Lower petal length & $\begin{array}{l}F \text { value } \\
\% \text { variance }\end{array}$ & 3.1 & $\begin{array}{r}7.2 \\
21.2\end{array}$ & $\begin{array}{l}8.6 \\
8.5\end{array}$ & $\begin{array}{l}1.5 \\
0\end{array}$ \\
\hline
\end{tabular}

* Plants were nested within substrate types. All sources of variation except substrate type were treated as random effects. Negative variance components have been set to zero. 
There is a significant individual variation in mean RW1 $(F=8.04, \mathrm{df}=50,178, P<.0001)$ and mean RW2 $(F=6.80, \mathrm{df}=50,178, P<.0001)$ scores, and a substantial proportion of observed variance in RW1 $(69.3 \%)$ and RW2 (57.5\%) is attributable to differences between plants. Plant mean scores on RW1 and RW2 will be used to characterize plants from the viewpoint of the shape of their corollas (see Floral morphology and fecundity below). To examine whether variation among plants in corolla shape was related to variation in corolla size (allometry), plant mean scores on RW1 and RW2 were regressed against their respective mean flower centroid sizes (square root of centroid size divided by the number of landmarks for each flower, a measure of "size"; Rohlf, in press, and documentation of TPSRW program). Neither mean RW1 $(F=0.28$, $\mathrm{df}=1,49, P=.59)$ nor RW2 $(F=1.14, \mathrm{df}=1,49$, $P=.29$ ) scores for individual plants were significantly related to mean flower centroid size, thus indicating that variation in flower shape was largely independent of size variation. Furthermore, multivariate analysis of variance was used to determine whether there existed some predictable relationship between substrate type and "average" shape of corolla outline of individual plants (as assessed by mean RW1 and RW2 scores). No significant overall effect of substrate type on corolla shape was found (Wilks' $\lambda=0.838$, approximate $F=2.18$, df $=4,94, P=.08$ ).

Floral morphology and fecundity. - The objective of
TABLE 8. Principal components analysis of the correlation matrix of mean size of flower parts for individual plants $(N$ $=53$ ) (rotated factor loadings). The heaviest loadings on each factor are shown in bold type.

\begin{tabular}{lccc}
\hline \hline & \multicolumn{3}{c}{ Factors } \\
\cline { 2 - 4 } Variable & PC1 & PC2 & PC3 \\
\hline & \multicolumn{3}{c}{ Factor loadings } \\
\cline { 2 - 4 } Upper petal length & $\mathbf{0 . 8 9 9}$ & 0.184 & 0.273 \\
Middle petal length & $\mathbf{0 . 9 3 6}$ & 0.140 & 0.269 \\
Lower petal length & $\mathbf{0 . 8 3 0}$ & 0.322 & 0.264 \\
Spur length & 0.228 & $\mathbf{0 . 9 4 8}$ & 0.213 \\
Peduncle length & 0.371 & 0.252 & $\mathbf{0 . 8 9 4}$ \\
\% variance explained & 51.3 & 22.4 & 21.2 \\
\hline
\end{tabular}

this section is to answer the question, Is there a significant relationship between the floral morphology and the fecundity of individual $V$. cazorlensis plants? Ordinary parametric (least squares) regression methods will first be used to assess the statistical significance of the relationship between fecundity and the variables describing floral morphology (Lande and Arnold 1983). For those traits exhibiting a significant relationship with fecundity (as assessed by partial regression coefficients), the shape of selection functions will then be evaluated by means of nonparametric regression (Schluter 1988).

The two sets of variables describing shape of corolla outline (mean RW1 and RW2) and size of flower parts
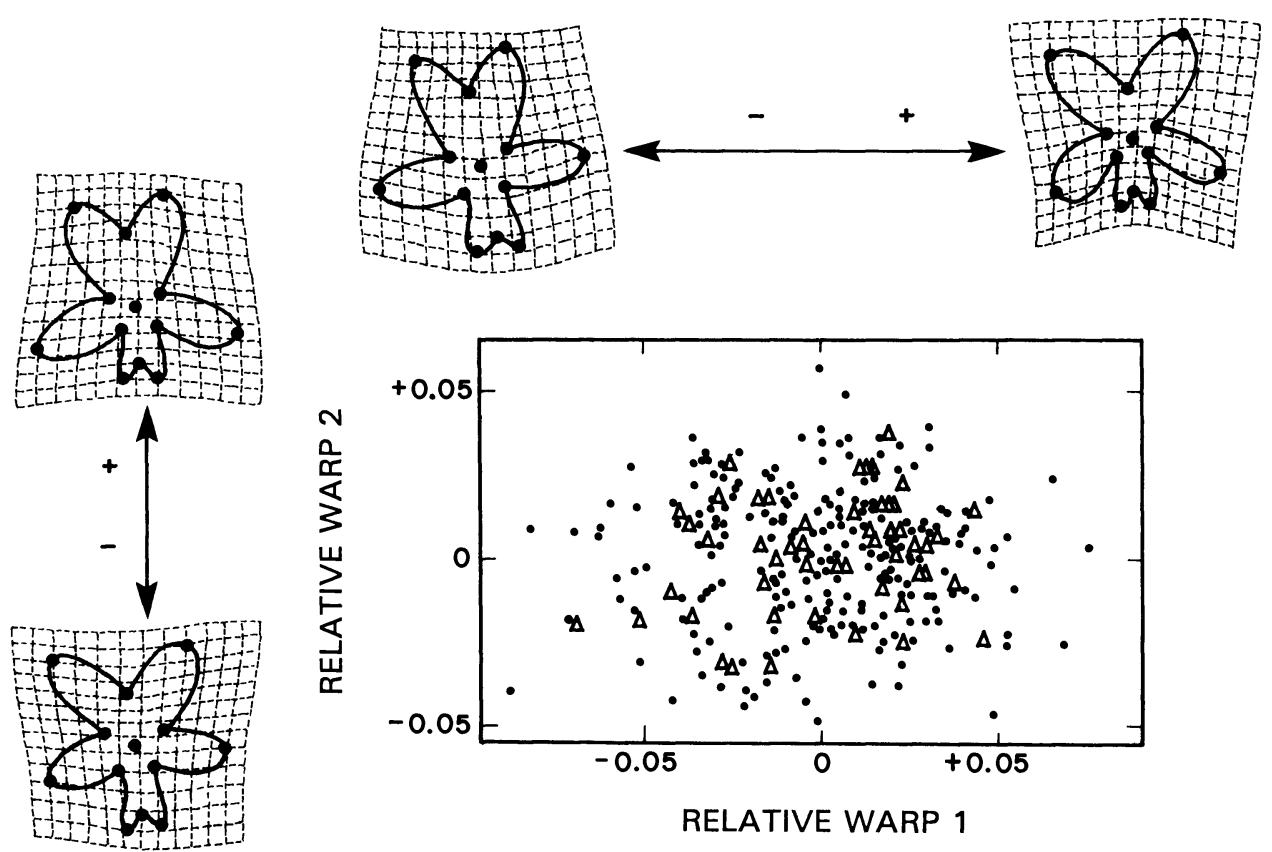

FIG. 7. Thin-plate spline relative warps analysis of variation in corolla shape (outline in front view) in a sample of marked Viola cazorlensis flowers. The position of all individual flowers used in the analyses $(N=229)$ on the plane defined by relative warps 1 and 2 is shown by dots, and triangles denote bivariate means for individual plants $(N=51)$. Changes in shape associated with each relative warp are depicted as deformations of an initial orthogonal grid overimposed on the average (consensus) configuration of landmarks. Location of the 13 landmarks used is shown as dots on the grids. To improve presentation, an idealized corolla outline is shown for each deformation grid. 
TABLE 9. Effect of floral morphology on the fecundity of individual $V$. cazorlensis plants $(N=48$ plants $) . b$, standard partial regression coefficient; $t$, Student's $t ; P$, significance of partial regression coefficient. Significant regression coefficients $(P<$ $.05)$ are shown in bold type.

\begin{tabular}{|c|c|c|c|c|c|c|}
\hline \multirow{2}{*}{$\begin{array}{l}\text { Independent } \\
\text { variable }\end{array}$} & \multicolumn{3}{|c|}{ Regression 1} & \multicolumn{3}{|c|}{ Regression 2} \\
\hline & $b$ & $t$ & $P$ & $b$ & $t$ & $P$ \\
\hline \multicolumn{7}{|l|}{ Size components } \\
\hline $\begin{array}{l}\mathrm{PC} 1 \\
(\mathrm{PC} 1)^{2} \\
\text { PC2 } \\
(\mathrm{PC} 2)^{2} \\
\text { PC3 } \\
(\mathrm{PC} 3)^{2}\end{array}$ & $\begin{array}{r}\mathbf{0 . 3 6 0} \\
-\mathbf{0 . 3 8 7} \\
-0.240 \\
-0.222 \\
0.115 \\
\mathbf{0 . 3 0 8}\end{array}$ & $\begin{array}{l}2.89 \\
3.06 \\
1.83 \\
1.67 \\
1.01 \\
2.39\end{array}$ & $\begin{array}{l}.006 \\
.004 \\
.075 \\
.10 \\
.32 \\
.022\end{array}$ & $\begin{array}{r}\mathbf{0 . 2 0 5} \\
-0.164 \\
-0.131 \\
-0.118 \\
0.003 \\
\mathbf{0 . 2 3 1}\end{array}$ & $\begin{array}{l}2.13 \\
1.61 \\
1.32 \\
1.17 \\
0.04 \\
2.39\end{array}$ & $\begin{array}{l}.040 \\
.12 \\
.19 \\
.25 \\
.97 \\
.022\end{array}$ \\
\hline \multicolumn{7}{|l|}{ Shape components } \\
\hline $\begin{array}{l}\text { RW1 } \\
(\text { RW1) } \\
\text { RW2 } \\
(\text { RW2)2 }\end{array}$ & $\begin{array}{l}-\mathbf{0 . 4 9 0} \\
\mathbf{- 0 . 4 2 8} \\
-\mathbf{0 . 3 3 9} \\
-0.231\end{array}$ & $\begin{array}{l}3.31 \\
2.94 \\
2.90 \\
1.96\end{array}$ & $\begin{array}{l}.002 \\
.006 \\
.006 \\
.058\end{array}$ & $\begin{array}{r}-\mathbf{0 . 3 6 3} \\
\mathbf{- 0 . 2 4 1} \\
-0.136 \\
0.003\end{array}$ & $\begin{array}{l}3.25 \\
2.14 \\
1.46 \\
0.03\end{array}$ & $\begin{array}{l}.003 \\
.039 \\
.15 \\
.98\end{array}$ \\
\hline Number of flowers & $\ldots$ & $\ldots$ & $\ldots$ & -0.600 & 5.63 & .0001 \\
\hline
\end{tabular}

The cumulative seed production of each plant over the 1988-1991 period (log transformed) was regressed on a set of variables describing its floral morphology. Independent variables were the principal component scores describing the size of flower parts (PC1-PC3, Table 8), the mean scores on the first two relative warps describing corolla outline (RW1-RW2, Fig. 2 ), and their squares (Regression 1). In Regression 2, cumulative flower production in the same period (log transformed) was also included among independent variables to account for individual differences in absolute flower production.

(PC1-PC3) of individual plants were included as independent variables in a multiple quadratic regression (Lande and Arnold 1983). Individual fecundity (estimated by either cumulative seed or fruit production, log transformed) over the 1988-1991 period was the dependent variable. Two separate analyses, conducted using fruit production and seed production as dependent variables, gave identical results. To save space, only the results of analyses conducted using seed production as the dependent variable are reported in this section, as that magnitude is a more direct estimate of fitness than fruit production.

Genetic interpretations of selection analyses require the use of untransformed fitness estimates (Lande and Arnold 1983). This procedure, however, may entail serious problems for tests of significance (Mitchell-Olds and Shaw 1987), particularly when data depart strongly from normality, as is the case with fecundity estimates for $V$. cazorlensis. Reliable statistical testing of morphology-fecundity relationships is more important for the purpose of this study than reliable estimates of selection coefficients, thus I chose to log-transform fecundity data to normalize them. Variables in each set of morphological descriptors (shape and size components) used in regression are uncorrelated. Furthermore, the two sets covary independently of each other across plants, as revealed by canonical correlation analysis (procedure CANCORR in SAS; Wilks' $\lambda=0.913$, approximate $F=0.67, \mathrm{df}=6,86, P=.67$ ). Results of significance tests will thus be unaffected by multicollinearity (Mitchell-Olds and Shaw 1987). Furthermore, regression coefficients for shape components are not expected to be seriously influenced by correlations between flower shape and overall size (Mitchell-Olds and Shaw 1987, Kingsolver and Schemske 1991), as it was shown earlier (Floral morphology: Corolla shape) that individual variation in RW1 and RW2 was unrelated to differences in overall flower size (as measured by mean centroid size).

There is a highly significant overall relationship between fecundity and floral morphology of individual plants, as revealed by multiple quadratic regression $(F$ $=4.85, \mathrm{df}=10,37, P=.0002$ ). All components of floral morphology examined except PC2 (spur length) are significantly related to seed production of individual plants. Significant regression coefficients were obtained for PC1 (size of petals), PC3 (peduncle length), mean RW1, and mean RW2 (corolla shape) (Table 9). For PC1, PC3, and RW1, the quadratic regression coefficients were significant, suggesting the existence of nonlinear selection functions (stabilizing or disruptive) on these morphological variables. When cumulative flower production (log transformed) was included among independent variables in regression to account for the strong influence of this variable on fecundity (Fig. 6), the absolute values of regression coefficients showed a slight decrease, but overall results experienced only minor variations ("Regression 2" in Table 9). This indicates that the relationship between floral morphology and fecundity is mainly a consequence of floral morphology influencing proportional fruit set.

Separate nonparametric regressions were used to evaluate the shape of selection functions on each of the floral traits that are significantly related to fecundity (PC1, PC3, RW1, RW2; Table 9). Nonparametric regression does not depend on a priori assumptions about the underlying mathematical function (in contrast to least squares based quadratic regression), thus it provides a more reliable appraisal of the shape of the relationship between dependent and independent vari- 


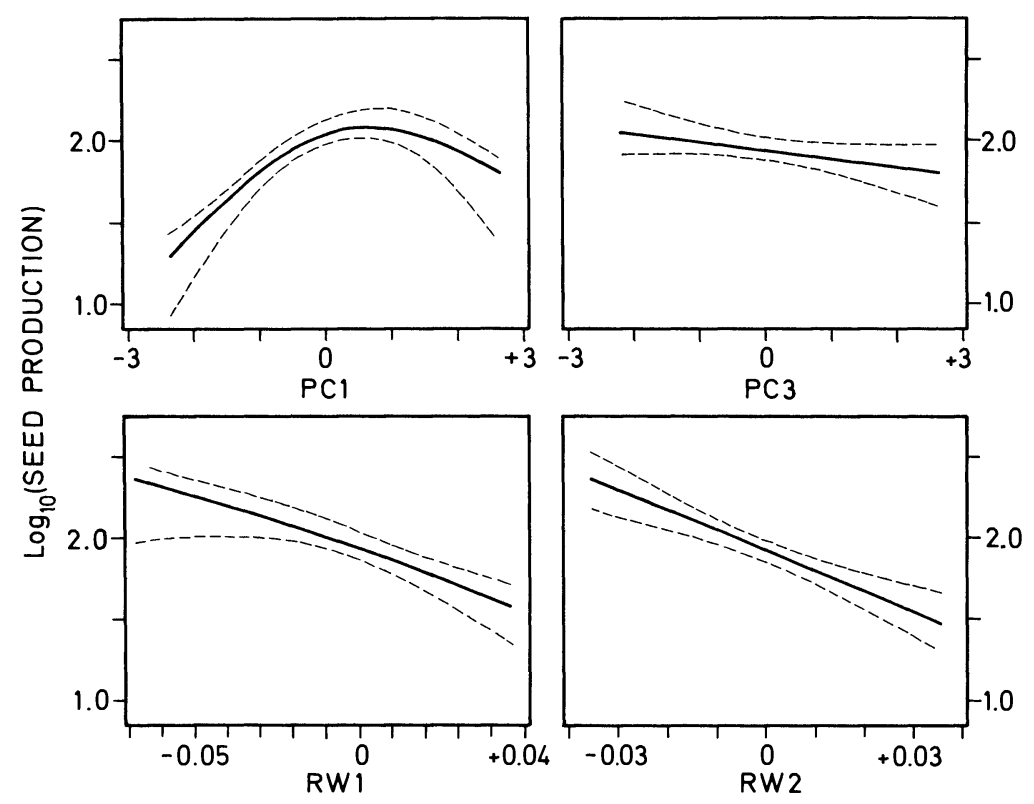

FIG. 8. Phenotypic selection functions on four morphological variables describing flower shape (RW1 and RW2; Fig. 7) and size (PCl and PC3; Table 8) components in Viola cazorlensis. Regression lines $(-)$ were fitted to fecundity (cumulative seed production over 1988-1991) and floral morphology data of individual plants $(N=53$ plants for PC1 and PC3; $N=51$ plants for RW1 and RW2) using a nonparametric, generalized cross-validation method (Schluter 1988). - - indicate \pm 1 SE of predicted values from 100 bootstrap regression replicates (see Results: Floral morphology: Floral morphology and fecundity).

ables (Schluter 1988). Cubic splines were fitted to the data using the generalized cross-validation method described in detail by Schluter (1988). To estimate the sampling variability of each regression line obtained, standard errors for the predicted values were obtained by generating 100 replicate bootstrap regressions on randomly resampled data (Schluter 1988). Results of nonparametric regressions are summarized in Fig. 8.

The nonlinearity of selection functions suggested by multiple regression for $\mathrm{PC} 1, \mathrm{PC} 3$, and RW1 (Table 9) was confirmed only for PC1 (size of petals). Plants with intermediate-sized corollas tended to produce significantly more seeds than those with either large or small corollas, thus revealing the existence of stabilizing phenotypic selection on this trait (Fig. 8). Selection functions on PC3, RW1, and RW2 were all essentially linear, and demonstrate the existence of directional phenotypic selection on these floral traits (Fig. 8). Seed production tends to decrease monotonically with increasing values of PC3, RW1, or RW2 (Fig. 8).

\section{Synthesis: Comparative importance of fecundity determinants}

The preceding sections have documented the influence of a variety of ecological and morphological factors on the fecundity of $V$. cazorlensis plants. The relative importance of, and interactions among, these factors in determining individual differences in fecundity will be examined in this section by applying path

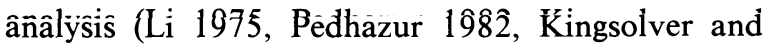
Schemske 1991, Mitchell 1992; see Schemske and
Horvitz 1988 for a detailed description of path analysis in an ecological context). The particular causal model selected to explain individual variation in seed production is depicted in Fig. 9, and may be summarized as follows. Substrate type determines differences among individuals in the impact of herbivores, and it also influences plant size and flower production per reproductive event. Plant size, in turn, influences the supraannual frequency of flowering and the number of flowers produced in each reproductive event. Herbivory effects, floral morphology, and flower production all have significant influences on fruit number that, along with the number of ovules per flower, are the major direct determinants of seed production. This particular causal model was chosen because it incorporates most parsimoniously all statistically significant relationships between variables documented in the preceding sections, and includes all ecological and morphological variables previously shown to influence fecundity significantly. The significant effect of floral morphology on fruit and seed production (see Floral morphology: Floral morphology and fecundity) was largely mediated by its influence on fruit set (see Interactions with animals: Pollination, and Table 9: Regression 2). For this reason, morphological variables were entered in the model as directly affecting fruit production.

Each plant was characterized by the following variables: size, substrate type, number of reproductive events over 1988-1991, cumulative number of fruits and seeds produced in the same period, average number of flowers produced per reproductive event, mean 


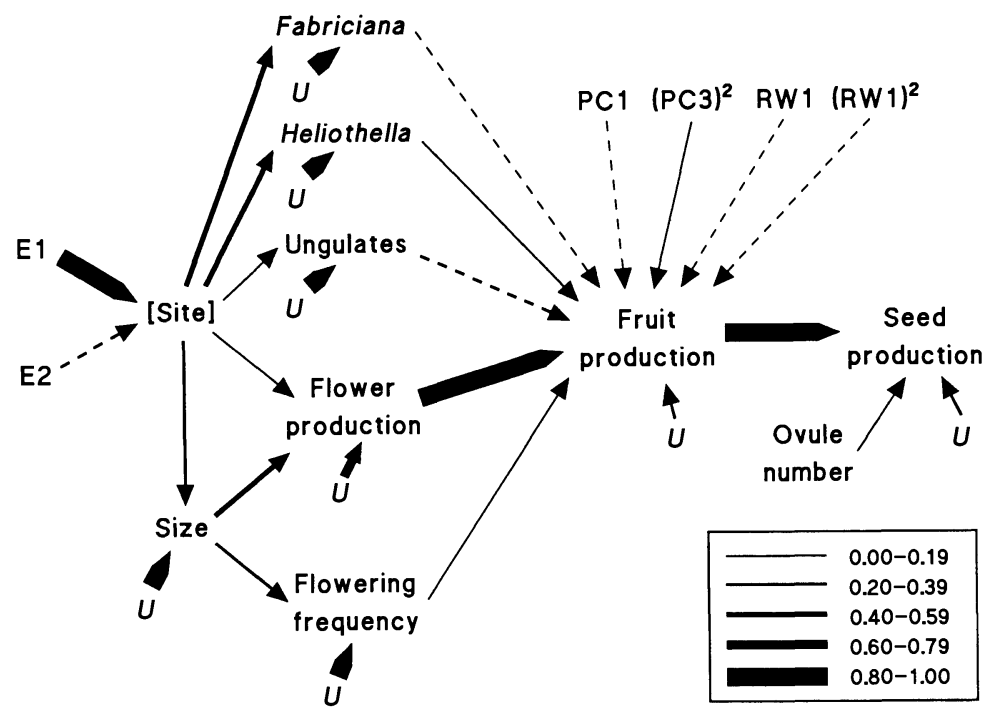

Fig. 9. Path diagram for the effects of substrate type, plant size, herbivores (Fabriciana adippe, Heliothella wulfeniana, and mammalian ungulates), mean flower production per reproductive event ("Flower production"), number of reproductive events ("Flowering frequency"), number of ovules per flower, and floral morphology (PC1, PC3, RW1, and RW3), on cumulative fruit and seed production of marked $V$. cazorlensis plants in the period 1988-1991. E1 and E2 stand for the two dummy variables used to code substrate type for the analysis, and "Site" is a latent variable representing an unmeasured ecological factor that varies among substrate types. Components of floral morphology included in the diagram were those having significant effects on fecundity (Table 9: Regression 2). Positive effects are indicated by -, and negative effects by - - - The magnitude of path coefficients is coded using different line widths (legend at lower right). Residual variables, representing the unmeasured factors that affect a given dependent variable, are represented by $U$ 's.

number of ovules per flower, mean effect of each of the three herbivores on flower or fruit production, and mean PC1, PC3, and RW1 scores (floral morphology). The mean impact of herbivores on each plant was computed as the 4-yr average of annual percentages of flowers (Fabriciana) and fruits (Heliothella, ungulates) eaten. The variable describing substrate type is of a qualitative nature. Prior to its inclusion in the analysis, it was effect-coded using two dummy variables (number of character states-1; Pedhazur 1982), and these were causally linked to a latent variable ("Site" hereafter) representing an unmeasured factor (Pedhazur 1982, Steiger 1989). This unmeasured "Site" factor was thus used as a quantitative surrogate for the qualitatively defined "substrate type." Some variables describing floral morphology (PC3, RW1) were nonlinearly related to fecundity (significant quadratic terms in regression; Table 9), thus violating one of the requirements of path analysis ( $\mathrm{Li}$ 1975, Pedhazur 1982, Crespi 1990). To overcome this problem, the appropriate quadratic terms were included in the model. Computation of path coefficients was performed using the program EzPATH (Steiger 1989) and a maximum likelihood estimation method. The path diagram in Fig. 9 illustrates the direction and magnitude of direct effects (path coefficients). Correlations involving fruit and seed production are decomposed into direct and indirect effects in Table 10, where effect coefficients (the sum of direct and indirect effects; Pedhazur 1982) are also shown.

The agreement between the model and the original data was assessed by means of the Gamma Index, $\Gamma_{1}$, described by Steiger (1989). $\Gamma_{1}$ can be thought of as a weighted population coefficient of determination for the multivariate model, and thus ranges from 0 (null fit) to 1 (perfect fit). Application of the more usual likelihood-ratio statistic to the present data was precluded by insufficient sample size (Steiger 1989, Mitchell 1992). The model depicted in Fig. 9 fits reasonably well the original data, as revealed by an estimated $\Gamma_{1}$ value of $0.890(90 \%$ confidence interval $=0.822-0.951)$.

Cumulative fruit production and number of ovules per flower account altogether for $89.9 \%$ of individual variation in cumulative seed production $\left(R^{2}\right.$ of regression). Fruit production has the greatest direct effect on seed production $(0.946)$, while that of ovule number is negligible (0.064). The proportion of variation in fruit production explained by the variables directly influencing it is $92.0 \%$. Mean flower production per reproductive event has the greatest direct effect $(0.918)$ on fruit production, followed by herbivory by ungulates $(-0.234)$. The importance of the other ecological factors directly influencing fruit production (herbivory by Fabriciana and Heliothella, frequency of flowering) is negligible in all cases. Similarly, variables describing floral morphology have small effect coefficients on fruit production. RW1, with a coefficient of -0.113 , is the morphological variable with the greatest effect on fruit production. As assessed by the sum of their respective $R^{2}$ values, the four morphological variables explain altogether only $2.1 \%$ of individual variation in cumulative fruit production. 
TABLE 10. Decomposition of the correlations of variables with number of fruits and number of seeds* into direct and indirect effects. The effect coefficient is the sum of the two effect components. Effect coefficients with absolute values $\geq 0.1$ are shown in bold type.

\begin{tabular}{|c|c|c|c|c|}
\hline & Variables in correlation & $\begin{array}{l}\text { Direct } \\
\text { effect }\end{array}$ & $\begin{array}{l}\text { Indirect } \\
\text { effect }\end{array}$ & $\begin{array}{c}\text { Effect } \\
\text { coefficient }\end{array}$ \\
\hline No. fruits & $\begin{array}{l}\text { [Site] } \\
\text { Fabriciana effect } \\
\text { Heliothella effect } \\
\text { Ungulate effect } \\
\text { Plant size } \\
\text { Mean flower production } \\
\text { Frequency of flowering } \\
\text { PC1 } \\
(\text { PC3) } \\
\text { RW1 } \\
(\mathrm{RW} 1)^{2}\end{array}$ & $\begin{array}{r}0 \\
-0.007 \\
0.038 \\
-\mathbf{0 . 2 3 4} \\
0 \\
\mathbf{0 . 9 1 8} \\
0.007 \\
-0.027 \\
0.084 \\
-\mathbf{0 . 1 1 3} \\
-0.005\end{array}$ & $\begin{array}{l}\text { 0.100 } \\
0 \\
0 \\
0 \\
\mathbf{0 . 4 6 6} \\
0 \\
0 \\
0 \\
0 \\
0 \\
0\end{array}$ & $\begin{array}{r}\mathbf{0 . 1 0 0} \\
-0.007 \\
0.038 \\
-\mathbf{0 . 2 3 4} \\
\mathbf{0 . 4 6 6} \\
\mathbf{0 . 9 1 8} \\
0.007 \\
-0.027 \\
0.084 \\
-\mathbf{0 . 1 1 3} \\
-0.005\end{array}$ \\
\hline No. seeds & $\begin{array}{l}\text { [Site] } \\
\text { Fabriciana effect } \\
\text { Heliothella effect } \\
\text { Ungulate effect } \\
\text { Plant size } \\
\text { Mean flower production } \\
\text { Frequency of flowering } \\
\text { Number of fruits } \\
\text { Mean ovule number } \\
\text { PC1 } \\
\text { (PC3) } \\
\text { RW1 } \\
(\text { RW1 } 1)^{2}\end{array}$ & $\begin{array}{l}0 \\
0 \\
0 \\
0 \\
0 \\
0 \\
0 \\
\mathbf{0 . 9 4 6} \\
0.064 \\
0 \\
0 \\
0 \\
0\end{array}$ & $\begin{array}{r}0.095 \\
-0.007 \\
0.036 \\
-\mathbf{0 . 2 2 1} \\
\mathbf{0 . 4 4 1} \\
\mathbf{0 . 8 6 8} \\
0.007 \\
0 \\
0 \\
-0.026 \\
0.079 \\
\mathbf{0 . 1 0 7} \\
-0.005\end{array}$ & $\begin{array}{r}0.095 \\
-0.007 \\
0.036 \\
-\mathbf{0 . 2 2 1} \\
\mathbf{0 . 4 4 1} \\
\mathbf{0 . 8 6 8} \\
0.007 \\
\mathbf{0 . 9 4 6} \\
0.064 \\
-0.026 \\
0.079 \\
\mathbf{0 . 1 0 7} \\
-0.005\end{array}$ \\
\hline
\end{tabular}

* Numbers of fruits and seeds represent the cumulative production by individual plants over the 4-yr study period. Variables PC1, PC3, and RW1 are descriptors of floral morphology significantly related to fruit production (Table 9: Regression 2). See Results: Synthesis: Comparative importance of fecundity determinants for a description of the remaining variables.

"Site" and plant size combined explain $26.6 \%$ of variation in flower production per event. The direct effect of plant size $(0.506)$ on flower production is considerably greater than that of "Site" $(0.100)$. "Site" has marked direct effects on the mean impact of Heliothella (0.458), Fabriciana (0.404), and ungulates (0.585) on $V$. cazorlensis plants.

The effect coefficients of all variables on cumulative seed production were obtained by summing their direct and indirect effects (Table 10). Mean flower production per event $(0.868)$ and cumulative fruit production $(0.946)$ yielded the largest effect coefficients, followed by plant size $(0.441)$, herbivory by ungulates $(-0.221)$, and RW1 score $(0.107)$. All the remaining variables have effect coefficients $<0.10$.

The consistency among years of patterns revealed by the path model based on all study years combined was examined by conducting separate path analyses for each study season. The fitted models were identical to the one depicted in Fig. 9, with the exception that the variables "flowering frequency" (describing supra-annual frequency of flowering) and "ovule number" (due to insufficient sample sizes when data were subdivided into 1-yr samples) were omitted for these yearly analyses. Furthermore, variables describing flower shape (RW1 and RW2) were available only for 1991. The fit of models to the original data varied slightly among years, but it was reasonably good in all cases. $\Gamma_{1}$ figures (and 90\% confidence intervals, in parentheses) for the models of 1988 through 1991 were, respectively, 0.842
(0.756-0.921), $0.851 \quad(0.762-0.932), 0.981 \quad(0.906-$ $1.000)$, and $0.839(0.767-0.906)$. The relative magnitudes of the effect coefficients of variables influencing plant fecundity were roughly similar in all years, and did not depart in any important way from those obtained for the $4 \mathrm{yr}$ combined.

\section{DISCUSSION}

\section{Monophily and floral specialization in V. cazorlensis}

$V$. cazorlensis is a genuine "rare" plant (Rabinowitz 1981), characterized by a very restricted geographic range, narrow habitat specificity, and small local populations. This ecological "rarity" goes along with salient peculiarities in its pollination system. The majority of Viola species are characterized by open corollas with externally visible androecia and gynoecia, the lower petal forms a "landing platform" for insect pollinators, the spur generally does not exceed $10 \mathrm{~mm}$ in length, and are pollinated by multispecies pollinator assemblages (Valentine 1962, Veerman and van Zon 1965, Valentine et al. 1968, Beattie 1969, 1971, 1972a, $b$, 1974). $V$. cazorlensis flowers, in contrast, have a closed corolla with an extremely narrow entrance (the androecium and gynoecium are not externally visible; Fig. 1), a very long, thin spur, and lack a landing platform due to the arrangement of petal blades on the vertical plane. This floral divergence (relative to most members of the genus Viola) is associated with mono- 
phily, as the species is pollinated by virtually a single hawk moth species.

Hawk moth pollination systems generally involve sets of Sphingidae rather than single species (Grant 1983, 1985, Haber 1984, Miller 1985, Jordano 1990), and documented cases of monophily are rare (Nilsson et al. 1985, 1987). In addition, mean spur length of $V$. cazorlensis flowers $(25.0 \mathrm{~mm})$ matches nearly perfectly the mean proboscis length of its pollinator $(26.4 \pm 2.0$ $\mathrm{mm}$, range $=23.0-31.0 \mathrm{~mm}, N=19$ specimens from the study area; C. M. Herrera, personal observation). These observations might suggest that $V$. cazorlensis and $M$. stellatarum participate in a coevolutionary relationship, and that the distinct floral morphology of this atypical violet has been shaped by the selective action of its pollinator. Available evidence is not consistent with this view. First, the $V$. cazorlensis-M. stellatarum species pair does not reflect a situation of mutual plant-pollinator dependence, but rather that of a specialized flower depending on a generalist forager, similar to that reported for the interaction between hawk moths and monophilic angraecoid orchids in Madagascar (Nilsson et al. 1985, 1987, see also Kislev et al. 1972). While $V$. cazorlensis depends almost exclusively on $M$. stellatarum for reproduction, this hawk moth is a broad generalist that visits the flowers of at least 26 plant species in my study area (Herrera 1992b). Furthermore, the geographical range of the hawk moth virtually comprises the European continent (plus northern Africa; Rougeot and Viette 1980). Second, as discussed in detail in the next section (Phenotypic selection on floral morphology), the present study has shown that spur length is the single character, among those examined, for which no evidence of phenotypic selection was found, despite its broad natural variability. This suggests that current selection by $M$. stellatarum on $V$. cazorlensis flowers, if any, is unrelated to the evolution of the long spur that characterizes this species. And third, V. cazorlensis is an old, relict endemic that originated in the Mediterranean area in the Pliocene (Melchior and Cuatrecasas 1935, Quézel et al. 1980) and is a survivor of one of the oldest lineages in its genus (Valentine 1962). M. stellatarum, in contrast, belongs to a widespread paleotropical genus comprising many extant species of day-flying moths (D. F. Owen 1969, and personal communication). V. cazorlensis monophily, and the close morphological matching with $M$. stellatarum, most likely represent a conspicuous example of regional "ecological fitting" (sensu Janzen 1985), and the distinctive floral features of this plant probably did not evolve in connection with its current pollinator.

\section{Phenotypic selection on floral morphology}

Cumulative seed production of individual V. cazorlensis plants depended significantly on average floral morphology, thus revealing the existence of phenotypic selection on the floral morphology of this species at the study population. This result confirms the earlier finding of Herrera (1990a) for this species, who found a significant relationship between peduncle length and fecundity using data from the same population obtained during a single study season, and reveals further relationships between components of floral morphology and fecundity. Both size (peduncle length, size of petals) and shape (corolla outline) components are involved in the relationship between flower morphology and fecundity documented in this study. Phenotypic selection is of a directional nature on most morphological components (PC3, RW1, RW2), and stabilizing on PCl (corolla size). Plants with corollas of intermediate size, short peduncles, or low scores on RW1 or RW2, are at a comparative fecundity advantage.

Descriptors of floral morphology used in this study (principal components and relative warps scores) are uncorrelated among themselves, and selection gradients associated with each of these are thus independent of each other. A previous investigation on the patterns of variation of floral morphology among disjunct $V$. cazorlensis populations (Herrera 1990b) revealed little integration of the floral phenotype in this species, as floral traits did not vary in unison among populations. In contrast to other insect-pollinated species (Berg 1960), floral variation was not governed by a dominant "size factor" similarly affecting all flower parts. Results of the present study, conducted at the within-population level, suggest that uncoordinated geographical variation of flower parts in $V$. cazorlensis may be attributed to decoupled selection regimes on the various elements that determine floral morphology.

An earlier study on the same population of $\mathrm{V}$. $\mathrm{ca}$ zorlensis (Herrera 1990a) revealed the existence of disruptive selection on peduncle length, and failed to find evidence of selection on size of petals. The disagreement between these earlier results and those reported here must be attributed to the more restricted data set used in the previous investigation (one single season) compared to the present one (four seasons). As found in other species (Campbell 1989a, $b$, Schemske and Horvitz 1989), patterns of selection on floral morphology may vary among years in $V$. cazorlensis, and a reliable assessment of the "prevailing" selection regime thus requires using data from several seasons. The prevailing selection regime may be appraised by either comparing separate selection patterns obtained on a year-by-year basis, or by combining morphological and fecundity data from several years into a single sample. The latter approach has been the one used here, for two reasons. First, for long-lived perennial species like $V$. cazorlensis, cumulative seed production of individual plants over several years will reflect differences in maternal fitness more realistically than a series of separate fecundity estimates obtained for different reproductive episodes. And second, as most $V$. cazor- 
lensis individuals at the study site fail to flower in one year or another, and supra-annual flowering is unsynchronized, separate assessments of selection regime on a year-by-year basis would be based on slightly different subsets of the population, and results from different years would not be strictly comparable. Unsynchronized supra-annual flowering analogous to that found in $V$. cazorlensis is common among species of longlived perennials (Ashton 1975, Janzen 1978, Piñero and Sarukhán 1982, Cook and Lyons 1983, Inghe and Tamm 1985, 1988, Hutchings 1987, Clark and Clark 1988). In these instances, separate assessment of selection regimes for different reproductive episodes would inevitably be based on different population subsamples, as some individuals will be missed from the sample on one year or another, and this may lead to annual differences in the frequency distribution of relevant reproductive characters in the population (Gilbert and Lee 1980). Apparent variation between years in selection regimes may thus be a spurious consequence of annual changes in the composition of the subset of the population that reproduces each season.

Depending on the trait involved, correlations between fecundity and floral morphology in insect-pollinated plants may be due to differential attractiveness of floral phenotypes to pollinators, differential pollination success due to morphologically induced variation in pollen deposition rate, or a combination of these. Among the floral traits examined here for $V$. cazorlensis, spur length is the only one that could directly affect pollen deposition rates via differential degree of matching with hawk moth proboscis length (Nilsson 1988, Robertson and Wyatt 1990). As discussed later in this section, this character is the single one for which no significant relationship with fecundity has been found in this study. In contrast, the observed relationships between the remaining floral characters (size of petals, peduncle length, shape of corolla outline) and fecundity may be attributed to differential attractiveness to pollinators. Insect pollinators have been shown to discriminate between conspecific plants on the basis of metric floral characters like corolla size and inflorescence height, leading to individual variation in flower visitation rates and reproductive success (Galen and Newport 1987, Stanton and Preston 1988, Galen 1989, Young and Stanton 1990, Stanton et al. 1991). It was unfortunate that the pollination system of $V$. cazorlensis, involving a single uncommon pollinator, precluded the assessment of differences among individual plants in pollinator visitation rates. Indirect evidence, however, supports the idea that pollinator discrimination among plants may be involved in morphology-dependent patterns of differential fecundity. The effect of floral morphology on fecundity was largely mediated by its significant influence on proportional fruit set (Table 9), and results of experimental hand-pollinations have shown that fruit set is affected by the frequency of pollination. Variability in this mag- nitude could thus reflect individual differences in rate of visitation by pollinators.

The absence of phenotypic selection on spur length, despite the broad variability exhibited by this trait, is particularly striking. For a long-spurred species like $V$. cazorlensis, the prevailing paradigm for the evolution of flowers with deep corolla tubes, first proposed by Darwin (1877:165-166), would have predicted the existence of directional selection on spur length and a reproductive advantage for individuals with larger-thanaverage corolla depths (Nilsson 1988). Results of this study not only do not support the prediction, but show that spur length is, among all the floral traits examined, the only one unrelated to fecundity. An ancillary prediction, advanced by Fenster (1991), states that phenotypic variation in flowers with deep corolla tubes should decrease with increasing tube depth, as a consequence of the parallel decline in pollinator diversity and increase in the strength of stabilizing and/or directional selection on corolla tube length. Data from tropical hummingbird-pollinated flowers provided support for this prediction (Fenster 1991). V. cazorlensis represents an outstanding example of virtually complete monophily, yet its marked variability in spur length militates against the prediction. Compared with the corolla tube of eight southern Spanish plant species pollinated also by long-tongued Lepidoptera (butterflies and hawk moths; range of mean corolla depths = 8.4-51.9 $\mathrm{mm}$ ), the spur of $V$. cazorlensis flowers exhibits the highest levels of intraspecific variability in length (Herrera 1988b). These results show that individual variation in spur length does not always translate into differential reproductive output and, consequently, that Darwin's model for the evolution of orchids with deep corolla tubes (tested and verified by Nilsson 1988) probably does not apply universally to all species with deep tubular corollas (see also Nilsson 1978, Miller 1981).

Investigations on the fecundity correlates of floral variation had traditionally dealt with discontinuously varying traits in polymorphic species (e.g., color, scent; Kay 1976, Hannan 1981, Waser and Price 1981, Galen 1985, Schoen and Clegg 1985, Stanton et al. 1986, Galen et al. 1987, Stanton 1987, Galen and Newport 1988). In recent years, an increasing number of studies have examined the reproductive correlates of intraspecific variation in metric floral characters (e.g., Nilsson 1988, Stanton and Preston 1988, Galen 1989, Robertson and Wyatt 1990, Young and Stanton 1990, Johnston 1991, Stanton et al. 1991). These investigations have generally shown, as found here, that individual variation in the size of flowers or their parts translates into differential reproductive success. The relationship between plant reproductive success and quantitative measures of flower shape, however, has not been examined previously for any species, even though the notion that flower shape has played a significant role in floral evolution is an essential element 
of all classical treatments of floral morphology (Leppik 1957, Stebbins 1970, Faegri and van der Pijl 1971, Weberling 1989). The absence of empirical studies relating flower form to reproductive success, despite some pioneering theoretical efforts (Davenport and Lee 1985), must be attributed to the practical complexities involved in the quantification of form (Rohlf 1990b, Rohlf and Bookstein 1990), that have historically hindered the development of objective morphometric methods (Bookstein 1990a). By applying Bookstein's (1990b, 1992) recent method of thin-plate splines relative warps analysis to flower landmark data, the present study has been able to demonstrate for the first time that individual differences in mean shape of corolla outline may be associated with differential fecundity, independently of variation in the size of individual flower parts. This result validates the suggestion of Beattie (1969), in reference to other Viola species, on the potential significance of variation in shape of corolla outline in this genus. Further studies are needed to test if phenotypic selection on flower shape, as documented here, is as widespread in nature as selection on floral metric traits has eventually proven to be. Some pollinators are able to remember, and discriminate among, different floral shapes (Anderson 1977, Gould 1985, 1986), and may use flower shape as a cue for assessing floral rewards (Pellmyr 1988). If these abilities are widespread among visually oriented insect pollinators, then selection on flower shape mediated by pollinator discrimination might be equally or more determinant than selection on metric traits in the evolution of floral morphology. In this regard, it is important to note that, for $V$. $c a$ zorlensis, the effect coefficient of RW1 on fecundity far exceeded those obtained for size-related floral descriptors (PC1, PC3).

\section{Proportional importance of fecundity determinants}

Flower and fruit production, plant size, substrate type, herbivory levels, and number of ovules per flower, explained collectively nearly all (89.9\%) of individual variation in fecundity of $V$. cazorlensis at the study site. Effect coefficients obtained from the path analysis show that individual variability in absolute flower and fruit production were, by far, the main determinants of differences in seed production in $V$. cazorlensis, as found in many other studies of natural plant populations (e.g., Schemske and Horvitz 1988, Campbell 1989b, Mazer et al. 1989, Thompson and Pellmyr 1989, Schwaegerle and Levin 1990, Herrera 1991). Variation in herbivory rates and number of ovules per flower, although having statistically significant effects on fecundity, were relatively unimportant in quantitative terms (except for a moderate negative effect of browsing by ungulates). The total flower and fruit production of plants over a given period depended on the number of flowering episodes and the mean number of flowers and fruits produced per episode. Plant size had signif- icant, independent effects on these two components and, due to these indirect effects, its effect coefficient on seed production ranked third in absolute value.

Substrate type was an important indirect determinant of fecundity in the $V$. cazorlensis population studied. Substrate influenced fecundity via its effect on herbivory rates, plant size, and mean flower production per reproductive episode. Many studies have shown that environmental heterogeneity, perceived by plants at a variety of spatial scales, is often responsible for a substantial part of within-population variability in fecundity. Spatial variation in microtopography, competitive regime, and/or availability of water and nutrients contribute to individual differences in size which, in turn, translate into differential fecundity (e.g., Thompson 1983, Hartgerink and Bazzaz 1984, Heywood and Levin 1986, Antonovics et al. 1987, Kadmon and Shmida 1990, Platenkamp and Foin 1990, Schwaegerle and Levin 1990). In the study site, variation among substrates in these environmental factors is also probably responsible for variation in size and flower production of $V$. cazorlensis plants, but no direct measurements are available to confirm this possibility.

Substrate-dependent herbivory levels found in this study also contributed in an important way to the influence of substrate type on fecundity. On average, ground plants incurred greater reproductive losses to Fabriciana, Heliothella, and ungulates than either cliff or rock ones, which exhibited similarly low herbivory levels. It is striking that the site-dependent pattern of herbivory was similar for the three herbivores, given their differences in body size, behavior, general ecology, and parts of plants attacked. Inaccessibility to ungulates might explain the negligible effect of these herbivores on cliff plants, but this explanation does not hold for the two lepidopterans. On the other hand, rock plants are as accessible to ungulates as ground plants, yet they were browsed to a much lesser degree. Differential herbivory levels may be explained by the marked differences between substrates in plant cover. At the study site, $V$. cazorlensis is the only species found growing on most rocks and cliffs, and individuals are sparsely scattered on these bare surfaces. On the ground, in contrast, $V$. cazorlensis plants form part of a fairly diverse community of shrubs and other lowlying plants. The impact of invertebrate herbivores on individual plants depends in part on the vegetational composition and structure of the plant's immediate vicinity (Williams 1983, Thomas 1986, Núñez-Farfán and Dirzo 1988, Holmes and Jepson-Innes 1989, Jordano et al. 1990), and ovipositing Fabriciana and $\mathrm{He}$ liothella females may concentrate searching in areas of high vegetation density. Vertebrate ungulates at the study site, on the other hand, tend to avoid rocky surfaces nearly devoid of vegetation while foraging, and concentrate browsing on the more rewarding shrubby patches on sandy soils (C. M. Herrera, personal observation). 
Although individual variation in aspects of flower size and shape are influential on seed production, it represents a minor, virtually negligible determinant of fecundity differentials. After accounting for the effects of substrate type, herbivory, plant size and flower production, individual variation in floral morphology explained a negligible proportion $(2.1 \%)$ of total variation in fruit production, the main determinant of fecundity (number of ovules per flower, that largely determines brood size, was a relatively unimportant determinant of seed production). In other words, phenotypic selection on the floral morphology of $V$. cazorlensis at the study population is almost inconsequential as a source of individual variation in maternal fitness, its effects being heavily "diluted" by the overwhelming influence of other factors. The opportunity for selection in this species at the study site, therefore, is only minimally attributable to phenotypic variance in floral morphology.

\section{Evolutionary inferences}

Results of this study suggest that evolutionary responses of $V$. cazorlensis to the current selection regime on floral morphology are very unlikely, unless the heritability of floral characters is extraordinarily high. Information on heritability of floral characters is not available, but repeatability measures (the ratio of between-individual to total variance, providing an upper estimate of heritability; Falconer 1989) for size of petals (range $0.28-0.46$ ), spur length (0.34), and peduncle length (0.78), do not support that possibility.

The use of maternal fecundity as an indirect estimate of fitness may limit evolutionary interpretations of the results of this study (Primack and Kang 1989). Hermaphroditic plants contribute genes to the next generation also via the male function (paternity), and the relative contributions to fitness of male and female functions may vary seasonally and among plants (Devlin and Stephenson 1987, Campbell 1989a, Mazer et al. 1989). Nevertheless, recent studies on natural populations of hermaphroditic plants have documented a close correlation (across individuals) between absolute measures of reproductive success via pollen (seeds sired) and ovules (seeds produced) (Broyles and Wyatt 1990, Devlin and Ellstrand 1990, Dudash 1991). Plants producing most flowers in a population tend to be, simultaneously, those producing most seeds and fathering most progeny, because of the close direct dependence of these two variables on absolute flower production. Maternal fecundity figures thus probably represent satisfactory estimates of fitness in most situations.

No information on longevity and reproductive lifespan is available for $V$. cazorlensis, as the use of destructive methods with this endangered species (Gómez Campo 1987) seemed inadvisable. The absence of mortality records over a 4-yr period among the 75 marked plants used in this study suggests, however, a very slow population turnover and, consequently, that individuals of this species may be very long lived. Fecundity patterns documented in this study, therefore, may not reliably describe individual differences in lifetime fecundity if comparatively fecund (on a shortterm basis) individuals incur reduced future survival or fecundity as a consequence of the "cost of reproduction" (Law 1979). This demographic cost of enhanced short-term reproduction, however, has been unequivocally proven to date for few species apart from some orchids (Horvitz and Schemske 1988, Calvo and Horvitz 1990, Primack and Hall 1990, Herrera 1991, and references therein). The limited data available do not support the existence of a cost of reproduction in $V$. cazorlensis, at least over the relatively reduced time span of this study. The ranking of fecundity remained consistent in the course of the study, and there was a positive relationship across plants between supra-annual frequency of flowering and mean flower (and fruit) production per reproductive episode (a negative relationship would be predicted if a short-term cost of reproduction exists).

\section{CONCLUSION}

The main conclusion emerging from this field study on $V$. cazorlensis is that selection on the floral phenotype, even when it occurs, may be largely irrelevant in evolutionary terms because other ecological factors are much more important determinants of fitness differences among plants. This study illustrates that a realistic assessment of the potential evolutionary relevance of selection on plant reproductive traits requires a quantitative evaluation, in its natural scenario, of the predictable consequences of such selection. Experimental studies on artificial plant populations are irreplaceable as a way of identifying the proximate biological mechanisms, and sources of phenotypic variability in reproductive characters, involved in selection. To achieve their proposed goal, however, these investigations require eliminating the influence on the selection process of many factors that, under natural conditions, may configure it decisively. Prominent among these, as revealed by this study, is the characteristic size structure exhibited by natural populations of perennial plants that determines a fecundity hierarchy and generates most individual variance in fecundity (Solbrig and Solbrig 1984, Weiner and Thomas 1986, Weiner 1988). When confronted with this dominant source of within-population variation in fecundity, the fitness consequences of variability in reproductive traits, even though significant, may become proportionally negligible, as found in this study.

\section{ACKNOWLEDGMENTS}

I am indebted to Manolo Carrión and Carlos A. Herrera for help with the field work; Arabia Sánchez (Bombyliidae) and Antonio Vives (Pyralidae) for insect determinations; Manolo Martínez and Alicia Prieto for technical help; Fred Bookstein for advice on methods; and Antonio García-Valdecasas, F. James Rohlf, and Dolph Schluter for making com- 
puter programs available to me. Randy Mitchell, Douglas Schemske, and an anonymous reviewer provided unusually detailed and constructive comments on an earlier version of this paper. The Agencia de Medio Ambiente authorized my work in the Sierra de Cazorla and provided invaluable facilities there. This work was supported by grant PB87-0452 from the Dirección General de Investigación Científica y Técnica, Ministerio de Educación y Ciencia.

\section{LiTERATURE Cited}

Anderson, A. M. 1977. Shape perception in the honey bee. Animal Behaviour 25:67-79.

Antonovics, J., K. Clay, and J. Schmitt. 1987. The measurement of small-scale environmental heterogeneity using clonal transplants of Anthoxanthum odoratum and Danthonia spicata. Oecologia (Berlin) 71:601-607.

Arnold S. J., and M. J. Wade. 1984a. On the measurement of natural and sexual selection: theory. Evolution 38:709719.

Arnold, S. J., and M. J. Wade. 1984b. On the measurement of natural and sexual selection: applications. Evolution 38: 720-734.

Ashton, D. H. 1975. Studies of flowering behaviour in $E u$ calyptus regnans F. Muell. Australian Journal of Botany 23 : 399-411.

Beattie, A. J. 1969. The floral biology of three species of Viola. New Phytologist 68:1187-1201

- 1971. Pollination mechanisms in Viola. New Phytologist 70:343-360.

- 1972a. The pollination ecology of Viola. 2. Pollen loads of insect-visitors. Watsonia 9:13-25.

- $1972 b$. Insect-visitors to three species of violet ( $\mathrm{Vi}$ ola) in England. Entomologist's Monthly Magazine 108:711

-1974. Floral evolution in Viola. Annals of the Missouri Botanical Garden 61:781-793.

Berg, R. L. 1960. The ecological significance of correlation pleiades. Evolution 14:171-180.

Biere, A. 1991. Parental effects in Lychnis flos-cuculi. II. Selection on time of emergence and seedling performance in the field. Journal of Evolutionary Biology 3:467-486.

Bookstein, F. L. 1990a. Introduction to methods for landmark data. Pages 215-225 in F. J. Rohlf and F. L. Bookstein, editors. Proceedings of the Michigan morphometrics workshop. Special Publication Number 2. University of Michigan Museum of Zoology, Ann Arbor, Michigan, USA

- 1990b. Higher-order features of shape change for landmark data. Pages 237-250 in F. J. Rohlf and F. L. Bookstein, editors. Proceedings of the Michigan morphometrics workshop. Special Publication Number 2. University of Michigan Museum of Zoology, Ann Arbor, Michigan, USA.

1992. Morphometric tools for landmark data. Cambridge University Press, Cambridge, England.

Broyles, S. B., and R. Wyatt. 1990. Paternity analysis in a natural population of Asclepias exaltata: multiple paternity, functional gender, and the "pollen-donation hypothesis." Evolution 44:1454-1468.

Calvo, R. N., and C. C. Horvitz. 1990. Pollinator limitation, cost of reproduction, and fitness in plants: a transitionmatrix demographic approach. American Naturalist 136: 499-516.

Campbell, D. R. 1989a. Measurements of selection in a hermaphroditic plant: variation in male and female pollination success. Evolution 43:318-334.

- $1989 \mathrm{~b}$. Inflorescence size: test of the male function hypothesis. American Journal of Botany 76:730-738.

Campbell, D. R., N. M. Waser, M. V. Price, E. A. Lynch, and R. J. Mitchell. 1991. Components of phenotypic selection: pollen export and flower corolla width in Ipomopsis aggregata. Evolution 45:1458-1467.
Clark, D. B., and D. A. Clark. 1988. Leaf production and the cost of reproduction in the Neotropical rain forest cycad, Zamia skinneri. Journal of Ecology 76:1153-1163.

Cook, R. E., and E. E. Lyons. 1983. The biology of Viola fimbriatula in a natural disturbance. Ecology 64:654-660.

Crespi, B. J. 1990. Measuring the effect of natural selection on phenotypic interaction systems. American Naturalist 135:32-47.

Crespi, B. J., and F. L. Bookstein. 1989. A path-analytic model for the measurement of selection on morphology. Evolution 43: 18-28.

Darwin, C. 1877. The various contrivances by which orchids are fertilised by insects. Second edition. Reprinted 1984. University of Chicago Press, Chicago, Illinois, USA.

Davenport, D., and H. Lee. 1985. Image analysis in the Orchidaceae. Journal of Theoretical Biology 114:199-222.

Devlin, B., and N. C. Ellstrand. 1990. Male and female fertility variation in wild radish, a hermaphrodite. American Naturalist 136:87-107.

Devlin, B., and A. G. Stephenson. 1987. Sexual variations among plants of a perfect-flowered species. American Naturalist 130:199-218.

Dieringer, G. 1991. Variation in individual flowering time and reproductive success of Agalinis strictifolia (Scrophulariaceae). American Journal of Botany 78:497-503.

Dudash, M. R. 1991. Plant size effects on female and male function in hermaphroditic Sabatia angularis (Gentianaceae). Ecology 72:1004-1012.

Faegri, K., and L. van der Pijl. 1971. The principles of pollination ecology. Third edition. Pergamon, Oxford, England.

Falconer, D. S. 1989. Introduction to quantitative genetics. Third edition. Wiley, New York, New York, USA.

Fenster, C. B. 1991. Selection on floral morphology by hummingbirds. Biotropica 23:98-101.

Galen, C. 1985. Regulation of seed-set in Polemonium viscosum: floral scents, pollination, and resources. Ecology 66: 792-797.

- 1989. Measuring pollinator-mediated selection on morphometric floral traits: bumblebees and the alpine sky pilot, Polemonium viscosum. Evolution 43:882-890.

Galen, C., and M. E. A. Newport. 1987. Bumble bee behavior and selection on flower size in the sky pilot, Polemonium viscosum. Oecologia (Berlin) 74:20-23.

Galen, C. A., and M. E. A. Newport. 1988. Pollination quality, seed set, and flower traits in Polemonium viscosum: complementary effects of variation in flower scent and size. American Journal of Botany 75:900-905.

Galen, C., and M. L. Stanton. 1991. Consequences of emergence phenology for reproductive success in Ranunculus adoneus (Ranunculaceae). American Journal of Botany 78: 978-988.

Galen, C., K. A. Zimmer, and M. E. A. Newport. 1987. Pollination in floral scent morphs of Polemonium viscosum: a mechanism for disruptive selection on flower size. Evolution 41:599-606.

Gilbert, N., and S. B. Lee. 1980. Two perils of plant population dynamics. Oecologia (Berlin) 46:283-284.

Gómez Campo, C., editor. 1987. Libro rojo de especies vegetales amenazadas de España Peninsular e Islas Baleares. Instituto para la Conservación de la Naturaleza, Madrid, Spain.

Goodall, C. 1991. Procrustes methods in the statistical analysis of shape. Journal of the Royal Statistical Society B 53: 285-339.

Gould, J. L. 1985. How bees remember flower shapes. Science 227:1492-1494.

- 1986. Pattern learning by honey bees. Animal Behaviour 34:990-997.

Grant, V. 1983. The systematic and geographical distribu- 
tion of hawkmoth flowers in the temperate North American flora. Botanical Gazette 144:439-449.

1985. Additional observations on temperate North American hawkmoth flowers. Botanical Gazette 146:517520.

Haber, W. A. 1984. Pollination by deceit in a mass-flowering tropical tree Plumeria rubra L. (Apocynaceae). Biotropica 16:269-275.

Hannan, G. L. 1981. Flower color polymorphism and pollination biology of Platystemon californicus Benth. (Papaveraceae). American Journal of Botany 68:233-243.

Hartgerink, A. P., and F. A. Bazzaz. 1984. Seedling-scale environmental heterogeneity influences individual fitness and population structure. Ecology 65:198-206.

Herrera, C. M. 1988a. The fruiting ecology of Osyris quadripartita: individual variation and evolutionary potential. Ecology 69:233-249.

- 1988b. Biología y ecología de Viola cazorlensis. I. Variabilidad de caracteres florales. Anales del Jardín Botánico de Madrid 45:233-246.

— 1989. Biología y ecología de Viola cazorlensis. II. Uso de sustratos, reproducción y consumo por los herbívoros. Anales del Jardín Botánico de Madrid 47:125-138.

- 1990a. The adaptedness of the floral phenotype in a relict endemic, hawkmoth-pollinated violet. 1. Reproductive correlates of floral variation. Biological Journal of the Linnean Society 40:263-274.

- $1990 \mathrm{~b}$. The adaptedness of the floral phenotype in a relict endemic, hawkmoth-pollinated violet. 2. Patterns of variation among disjunct populations. Biological Journal of the Linnean Society 40:275-291.

— 1991. Dissecting factors responsible for individual variation in plant fecundity. Ecology 72:1436-1448.

- 1992a. Individual flowering time and maternal fecundity in a summer-flowering Mediterranean shrub: making the right prediction for the wrong reason. Acta Oecologica 13:13-24.

- $1992 b$. Activity pattern and thermal biology of a day-flying hawkmoth (Macroglossum stellatarum) under Mediterranean summer conditions. Ecological Entomology 17:52-56.

Heywood, J. S., and D. A. Levin. 1986. Interactions between seed source, planting arrangement, and soil treatment in determining plant size and root allocation in Phlox drummondii. Oecologia (Berlin) 68:285-290.

Holmes, R. D., and K. Jepson-Innes. 1989. A neighborhood analysis of herbivory in Bouteloua gracilis. Ecology 70:971976.

Horvitz, C. C., and D. W. Schemske. 1988. Demographic cost of reproduction in a neotropical herb: an experimental field study. Ecology 69:1741-1745.

Howe, H. F., and J. Smallwood. 1982. Ecology of seed dispersal. Annual Review of Ecology and Systematics 13:201228.

Hutchings, M. J. 1987. The population biology of the early spider orchid, Ophrys sphegodes Mill. I. A demographic study from 1975 to 1984 . Journal of Ecology 75:711-727.

Inghe, O., and C. O. Tamm. 1985. Survival and flowering of perennial herbs. IV. The behaviour of Hepatica nobilis and Sanicula europaea on permanent plots during 19431981. Oikos 45:400-420.

Inghe, O., and C. O. Tamm. 1988. Survival and flowering of perennial herbs. V. Patterns of flowering. Oikos 51:203219.

Janzen, D. H. 1978. Seeding patterns of tropical trees. Pages 83-128 in P. B. Tomlinson and M. H. Zimmermann, editors. Tropical trees as living systems. Cambridge University Press, New York, New York, USA.

. 1985. On ecological fitting. Oikos 45:308-310.

Johnston, M. O. 1991. Natural selection on floral traits in two species of Lobelia with different pollinators. Evolution 45:1468-1479.

Johnston, M. R., R. E. Tabachnick, and F. L. Bookstein. 1991. Landmark-based morphometrics of spiral accretionary growth. Paleobiology 17:19-36.

Jordano, D., J. Fernández Haeger, and J. Rodríguez. 1990. The effect of seed predation by Tomares ballus (Lepidoptera: Lycaenidae) on Astragalus lusitanicus (Fabaceae): determinants of differences among patches. Oikos 57:250256.

Jordano, P. 1990. Biología de la reproducción de tres especies del género Lonicera (Caprifoliaceae) en la Sierra de Cazorla. Anales del Jardín Botánico de Madrid 48:31-52.

Kadmon, R., and A. Shmida. 1990. Patterns and causes of spatial variation in the reproductive success of a desert annual. Oecologia (Berlin) 83:139-144.

Kalisz, S. 1986. Variable selection on the timing of germination in Collinsia verna (Scrophulariaceae). Evolution 40:479-491.

Kay, Q. O. N. 1976. Preferential pollination of yellow-flowered morphs of Raphanus raphanistrum by Pieris and Eristalis spp. Nature 261:230-232.

Kingsolver, J. G., and D. W. Schemske. 1991. Path analyses of selection. Trends in Ecology and Evolution 6:276-280.

Kislev, M. E., Z. Kraviz, and J. Lorch. 1972. A study of hawkmoth pollination by a palynological analysis of the proboscis. Israel Journal of Botany 21:57-75.

Knoll, F. 1922. Lichtsinn und Blütenbesuch des Falters von Macroglossum stellatarum. Abhandlungen der Zoologischbotanischen Gesellschaft in Wien 12:127-378.

Lande, R., and S. J. Arnold. 1983. The measurement of selection on correlated characters. Evolution 37:1210-1226.

Law, R. 1979. The cost of reproduction in annual meadow grass. American Naturalist 113:3-16.

Leppik, E. E. 1957. Evolutionary relationship between entomophilous plants and anthophilous insects. Evolution 11: $466-481$

Levin, D. A. 1969. The effect of corolla color and outline on interspecific pollen flow in Phlox. Evolution 23:444455.

Li, C. C. 1975. Path analysis-a primer. Boxwood Press, Pacific Grove, California, USA.

Lovett Doust, J. L., and L. L. Lovett Doust, editors. 1988. Plant reproductive ecology: patterns and strategies. Oxford University Press, New York, New York, USA.

Mazer, S. J., R. R. Nakamura, and M. L. Stanton. 1989. Seasonal changes in components of male and female reproductive success in Raphanus sativus L. (Brassicaceae). Oecologia (Berlin) 81:345-353.

Melchior, H., and J. Cuatrecasas. 1935. La Viola cazorlensis, su distribución, sistemática y biología. Cavanillesia 7:133148.

Miller, R. B. 1981. Hawkmoths and the geographic patterns of floral variation in Aquilegia caerulea. Evolution 35:763774.

. 1985. Hawkmoth pollination of Aquilegia chrysantha (Ranunculaceae) in southern Arizona. Southwestern Naturalist 30:69-76.

Mitchell, R. J. 1992. Testing evolutionary and ecological hypotheses using path analysis and structural equation modelling. Functional Ecology 6:123-129.

Mitchell-Olds, T., and R. G. Shaw. 1987. Regression analysis of natural selection: statistical inference and biological interpretation. Evolution 41:1149-1161.

Mitchell-Olds, T., and R. G. Shaw. 1990. Comments on the causes of natural selection. Evolution 44:2158.

Nilsson, L. A. 1978. Pollination ecology and adaptation in Platanthera chlorantha (Orchidaceae). Botaniska Notiser 131:35-51.

. 1988. The evolution of flowers with deep corolla tubes. Nature 334:147-149. 
Nilsson, L. A., L. Jonsson, L. Rason, and E. Randrianjohany. 1985. Monophily and pollination mechanisms in Angraecum arachnites Schltr. (Orchidaceae) in a guild of longtongued hawk-moths (Sphingidae) in Madagascar. Biological Journal of the Linnean Society 26:1-19.

Nilsson, L. A., L. Jonsson, L. Ralison, and E. Randrianjohany. 1987. Angraecoid orchids and hawkmoths in central Madagascar: specialized pollination systems and generalist foragers. Biotropica 19:310-318.

Núñez-Farfán, J., and R. Dirzo. 1988. Within-gap spatial heterogeneity and seedling performance in a Mexican tropical forest. Oikos 51:274-284.

Owen, D. F. 1969. Species diversity and seasonal abundance in tropical Sphingidae (Lepidoptera). Proceedings of the Royal Entomological Society of London, A 44:162-168.

Pedhazur, E. J. 1982. Multiple regression in behavioral research. Second edition. Holt, Rinehart and Winston, New York, New York, USA

Pellmyr, O. 1988. Bumble bees (Hymenoptera: Apidae) assess pollen availability in Anemonopsis macrophylla (Ranunculaceae) through floral shape. Annals of the Entomological Society of America 81:792-797.

Piñero, D., and J. Sarukhán. 1982. Reproductive behaviour and its individual variability in a tropical palm, Astrocaryum mexicanum. Journal of Ecology 70:461-472.

Platenkamp, G. A. J., and T. C. Foin. 1990. Ecological and evolutionary importance of neighbors in the grass Anthoxanthum odoratum. Oecologia (Berlin) 83:201-208.

Primack, R. B., and P. Hall. 1990. Costs of reproduction in the pink lady's slipper orchid: a four-year experimental study. American Naturalist 136:638-656.

Primack, R. B., and H. Kang. 1989. Measuring fitness and natural selection in wild plant populations. Annual Review of Ecology and Systematics 20:367-396.

Quézel, P., J. Gamisans, and M. Gruber. 1980. Biogéographie et mise en place des flores méditerranéennes. Naturalia Monspeliensia, Hors Série: 41-51.

Rabinowitz, D. 1981. Seven forms of rarity. Pages 205-217 in $\mathrm{H}$. Synge, editor. The biological aspects of rare plant conservation. John Wiley \& Sons, London, England.

Rathcke, B., and E. P. Lacey. 1985. Phenological patterns of terrestrial plants. Annual Review of Ecology and Systematics 16:179-214.

Real, L., editor. 1983. Pollination biology. Academic Press, Orlando, Florida, USA.

Robertson, J. L., and R. Wyatt. 1990. Evidence for pollination ecotypes in the yellow-fringed orchid, Platanthera ciliaris. Evolution 44:121-133.

Rohlf, F. J. 1990a. Rotational fit (Procrustes) methods. Pages 227-236 in F. J. Rohlf and F. L. Bookstein, editors. Proceedings of the Michigan morphometrics workshop. Special Publication Number 2. University of Michigan Museum of Zoology, Ann Arbor, Michigan, USA.

- 1990b. Morphometrics. Annual Review of Ecology and Systematics 21:299-316.

- In press. Relative warp analysis and an example of its application to mosquito wings. In L. F. Marcus, E. Bello and A. G. Valdecasas, editors. Contributions to morphometrics. Oxford University Press, Oxford, England.

Rohlf, F. J., and F. L. Bookstein, editors. 1990. Proceedings of the Michigan morphometrics workshop. Special Publication Number 2. University of Michigan Museum of Zoology, Ann Arbor, Michigan, USA.

Rohlf, F. J., and D. Slice. 1990. Extensions of the Procrustes method for the optimal superposition of landmarks. Systematic Zoology 39:40-59.

Rougeot, P. C., and P. Viette. 1980. Guía de campo de las mariposas nocturnas de Europa y norte de Africa. Omega, Barcelona, Spain.

SAS. 1988. SAS/STAT user's guide. Release 6.03 edition. SAS Institute, Cary, North Carolina, USA.
Schemske, D. W., and C. C. Horvitz. 1988. Plant-animal interactions and fruit production in a neotropical herb: a path analysis. Ecology 69:1128-1137.

Schemske, D. W., and C. C. Horvitz. 1989. Temporal variation in selection on a floral character. Evolution 43:461465.

Schluter, D. 1988. Estimating the form of natural selection on a quantitative trait. Evolution 42:849-861.

Schoen, D. J., and M. T. Clegg. 1985. The influence of flower color on outcrossing rate and male reproductive success in Ipomoea purpurea. Evolution 39:1242-1249.

Schwaegerle, K. E., and D. A. Levin. 1990. Environmental effects on growth and fruit production in Phlox drummondii. Journal of Ecology 78:15-26.

Solbrig, O. T., and D. J. Solbrig. 1984. Size inequalities and fitness in plant populations. Oxford Surveys in Evolutionary Biology 1:141-159.

Stanton, M. L. 1987. Reproductive biology of petal color variants in wild populations of Raphanus sativus. I. Pollinator response to color morphs. American Journal of Botany 74:178-187.

Stanton, M. L., and R. E. Preston. 1988. Ecological consequences and phenotypic correlates of petal size variation in wild radish, Raphanus sativus (Brassicaceae). American Journal of Botany 75:528-539.

Stanton, M. L., A. A. Snow, and S. N. Handel. 1986. Floral evolution: attractiveness to pollinators increases male fitness. Science 232:1625-1627.

Stanton, M., H. J. Young, N. C. Ellstrand, and J. M. Clegg. 1991. Consequences of floral variation for male and female reproduction in experimental populations of wild radish, Raphanus sativus L. Evolution 45:268-280.

Stebbins, G. L. 1970. Adaptive radiation in angiosperms. I. Pollination mechanisms. Annual Review of Ecology and Systematics 1:307-326.

Steiger, J. H. 1989. EzPATH: a supplementary module for SYSTAT and SYGRAPH. SYSTAT, Evanston, Illinois, USA.

Thomas, C. D. 1986. Butterfly larvae reduce host plant survival in vicinity of alternative host species. Oecologia (Berlin) 70:113-117.

Thompson, J. N. 1983. Partitioning of variance in demography: within-patch differences in herbivory, survival, and flowering of Lomatium farinosum (Umbelliferae). Oikos 40:315-317.

Thompson, J. N., and O. Pellmyr. 1989. Origins of variance in seed number and mass: interaction of sex expression and herbivory in Lomatium salmoniflorum. Oecologia (Berlin) 79:395-402.

Valentine, D. H. 1962. Variation and evolution in the genus Viola. Preslia 34:190-206.

Valentine, D. H., H. Merxmüller, and A. Schmidt. 1968. Viola L. Pages 270-282 in T. G. Tutin, V. H. Heywood, N. A. Burges, D. M. Moore, D. H. Valentine, S. M. Walters, and D. A. Webb, editors. Flora Europaea. Volume 2. Cambridge University Press, Cambridge, England.

Veerman, A., and J. C. J. van Zon. 1965. Insect pollination of pansies (Viola spp.). Entomologia Experimentalis et Applicata 8:123-134.

Wade, M. J., and S. Kalisz. 1990. The causes of natural selection. Evolution 44:1947-1955.

Waser, N. M., and M. V. Price. 1981. Pollinator choice and stabilizing selection for flower color in Delphinium nelsonii. Evolution 35:376-390.

Weberling, F. 1989. Morphology of flowers and inflorescences. Translated by R. J. Pankhurst. Cambridge University Press, Cambridge, England.

Weiner, J. 1988. The influence of competition on plant reproduction. Pages 228-245 in J. L. Lovett Doust and L. L. Lovett Doust, editors. Plant reproductive ecology: patterns 
and strategies. Oxford University Press, New York, New York, USA.

Weiner, J., and S. C. Thomas. 1986. Size variability and competition in plant monocultures. Oikos 47:211-222.

Widén, B. 1991. Phenotypic selection on flowering phenology in Senecio integrifolia, a perennial herb. Oikos 61:205215.
Williams, K. S. 1983. The coevolution of Euphydryas chalcedona butterflies and their larval host plants. III. Oviposition behavior and host plant quality. Oecologia (Berlin) 56:336-340.

Young, H. J., and M. L. Stanton. 1990. Influences of floral variation on pollen removal and seed production in wild radish. Ecology 71:536-547. 